\title{
Are Bid Preferences Benign? The Effect of Small Business Subsidies in Highway Procurement Auctions
}

\author{
Justin Marion * \\ Department of Economics \\ University of California, Santa Cruz
}

First Version: October 2004

This version: December 2006

\begin{abstract}
Bid preferences in procurement auctions allow firms from an identifiable group an advantage in bidding against unfavored firms. While economic efficiency is expected to fall as a result of bid preferences, government procurement costs may either increase or decrease depending on the competitive response of favored and unfavored firms. This paper uses data from California auctions for road construction contracts, where small businesses receive a five percent bid preference in auctions for projects using only state funds and no preferential treatment on projects using federal aid. I show that while firms' bidding behavior matches theoretical predictions, procurement costs are 3.8 percent higher on auctions using preferences. The higher procurement cost in preference auctions is attributed to reduced participation by lower cost large firms.

Structural estimates of latent firm costs are then used to evaluate how efficiency and the division of surplus between firms and the government are impacted by bid preferences. Firm profits are 3.1 percent lower under bid preferences, however this is overwhelmed by the efficiency loss due to reduced large firm participation. The efficiency loss conditional on firm participation is estimated to represent around 0.1 percent of overall procurement costs. Including the adverse effect of preferences on the participation of large firms increases the estimated efficiency loss to 3.6 percent, which represents 27 cents for each additional dollar awarded to small businesses through the program. Counterfactual simulations indicate that if participation were instead inelastic to bid preferences, the 5 percent bid preference would be close to the optimal level.
\end{abstract}

JEL Classification: H11, H4, H57, D44

${ }^{*}$ I would like to thank Marianne Bertrand, Jonathan Guryan, Ali Hortacsu, and Steve Levitt for their guidance and support. I also appreciate the helpful comments of Jeremy Fox, Matthew Gentzkow, Ricard Gil, Jonathan Levin, Jagadeesh Sivadasan, Chad Syverson, Donald Wittman, two anonymous referees, and seminar participants at the Stanford Institute for Theoretical Economics, Chicago GSB, Clemson, Cornell, Harvard KSG, Illinois-Chicago, Kentucky Martin School, Missouri-Columbia, Queen's University, UC-Santa Cruz, and the University at Buffalo. Financial support from the University of California Labor and Employment Research Fund is gratefully acknowledged. Address: Department of Economics, UC Santa Cruz, 401 Engineering 2, Santa Cruz, CA 95064. E-mail: marion@ucsc.edu. 


\section{Introduction}

Public procurement of goods and services is a significant and commonly used means to reallocate resources across economic agents. Through various preference programs, the U.S. federal government in 2001 awarded $\$ 21.3$ billion of procurement contracts to small firms, minority and women owned businesses, companies located in economically disadvantaged areas, and veteran-owned businesses. This represents nearly 10 percent of the $\$ 216$ billion federal procurement market. In addition, favored status is afforded to domestic producers in federal procurement, and a multitude of similar programs have been implemented at the state and local level. Reallocation through asymmetric treatment in procurement is generally thought to result in a loss in efficiency by increasing government purchases of goods from less efficient suppliers.

Bid preferences are one tool commonly used in procurement auctions to favor particular sellers. ${ }^{1}$ A typical bid preference program awards a procurement contract to the lowest favored bidder if its bid is within a certain percentage of the low bid from the unfavored group. Since they achieve redistribution by transferring contracts from unfavored firms to higher cost favored firms, bid preferences directly result in a loss of productive efficiency.

However, several theoretical results suggest that while bid preferences lower efficiency, they may also act to lower a government's procurement cost. Maskin and Riley (2000) and Myerson (1981) show that in asymmetric auctions only in specific cases does the optimal auction design always award the contract to the low cost firm. McAfee and McMillan (1989) in particular show that bid preferences can reduce the government's procurement cost through their effect on the competitive interaction between favored and unfavored firms. ${ }^{2}$ As a result, direct losses in efficiency are potentially mitigated since government expenditure is in practice financed through distortionary taxation.

\footnotetext{
${ }^{1}$ In $2001 \$ 137$ million of federal procurement contracts were awarded through bid preferences to small disadvantaged businesses and firms located in economically disadvantaged areas. Currently 17 states favor in-state bidders, the federal government awards a 6 percent bid credit to domestic firms through the Buy America Act and a 10 percent bid credit to small disadvantaged businesses.

${ }^{2}$ Several extensions to this theory are worth noting. First, Harstad, Rothkopf, and Fu (2003) obtain similar results for the effects of bid preferences in a common values setting. Cabral and Greenstein (1990) analyze the computer procurement market, where incumbent providers have a cost advantage, and therefore the buyer has incentive to favor non-incumbents to encourage competition. Rezende (2004a) has also considered the case where the product to be provided by the stronger and weaker supplier also differs on an unobserved dimension. The government biases the procurement auction toward the favored seller balancing the competing objectives of achieving an efficient allocation and encouraging competition. Vagstad (1995) considers a procurement setting with domestic and international suppliers, where governments discriminate in favor of domestic suppliers. He considers a case where quality is unobserved, and analyzes the implications for interventions by trade governing bodies.
} 
Instituting bid preferences can be optimal for the government if there are identifiable groups with different costs. Without preferences, low cost firms face weaker competition and earn higher rents than high cost firms. If bid preferences are instituted that favor the high cost firms, then the effective competition faced by the low cost firms increases. These firms are then forced to bid closer to costs, which acts to lower the winning bid.

Three factors could act to increase procurement costs. First, preferences may allow favored firms to increase their bid. Second, preferences transfer some contracts from low cost to high cost firms. Finally, the participation of large firms could be adversely affected, leading to higher cost participants or less competition.

This paper will examine the program of the California Department of Transportation (Caltrans), which provides bid preferences for small businesses in auctions for road construction contracts, to address two questions. First, do bid preferences affect the bidding behavior of favored and unfavored firms as predicted? Second, what is the impact of the preference program on procurement costs and efficiency?

Bid preferences in this program are applied to auctions for contracts using only state funds and are not applied to auctions for contracts using federal funds. In the first portion of the paper, I will exploit this distinction to identify the impact of preferences on bidding behavior and procurement costs. The average winning bid on preference projects is found to be 3.8 percent higher than for similar non-preference projects. Some of this difference is explained by reduced participation of large firms on preference auctions. When controls for the number of small and large bidders are included the estimated impact of preference auctions falls to 2.0 percent. The remaining is explained by the different composition of auction winners under preferences, which results from higher cost participants as well as shifting some contracts to higher cost firms. After controlling for firm effects the estimated impact of preferences on procurement costs falls to -0.5 percent.

Small firms are found to bid 1.6 percent higher than large firms, and conditional on firm participation patterns this difference grows by 1.5 percent on preference auctions. This suggests that bid preferences lead to some combination of large firms bidding more aggressively and small firms bidding less aggressively. While this bidding pattern is consistent with theory, the participation patterns of firms negates any benefits arising from strategic bidding behavior. Large firms show up less often on preference auctions, a significant proportion of which is due to substitution between preference and non-preference auctions.

The reduced form model of procurement costs informs how preferences affect the average winning bid, however it is unable to distinguish between a loss of surplus and a shift in surplus between 
the government and firms. The second half of the paper uses a structural model to investigate the loss in efficiency resulting from the use of preferences and apportions this loss between the effect of preferences altering the winning bidder and the effect of firm participation patterns. I employ the nonparametric techniques of Guerre, Perrigne, and Vuong (2000) to obtain structural estimates of latent firm costs on both preference and non-preference auctions. I find that by awarding fewer contracts to the low cost firm, preferences increased construction costs by 0.1 percent. Two sets of preference auctions are then simulated to estimate the effect of participation patterns on the construction cost of the winning firm. One simulation uses the distribution of participants on preference auctions, while the other uses the counterfactual distribution of participants observed on auctions not using preferences. Participation patterns are found to be responsible for a 3.6 percent increase in the cost of the winning firm. The results indicate that each additional dollar awarded to small businesses is associated with a 20 cent loss in efficiency, however if participation were inelastic to preferences this loss would be only 3.4 cents.

Lastly, the paper considers counterfactual simulations of different levels of the bid preference rate. With endogenous participation, procurement costs are higher at all preference levels. However if participation were held fixed at non-preference levels a bid preference of 5 percent is close to optimal.

This paper represents the first systematic empirical evaluation of a bid preference program taking into account the strategic response of firms. Older estimates of the effect of bid preferences on procurement cost, such as Lowinger (1976), ignore the competitive response of favored and unfavored firms. More recent papers have used simulation exercises to evaluate the effect of bid preferences. A recent paper by Krasnokutskaya and Seim (2006) also use data from Caltrans highway auctions to estimate a structural model of bidder participation in bid preference auctions. They estimate the cost distributions and entry costs from only those auctions using bid preferences, and use these distributions to conduct counterfactual simulations for different preference programs. By focusing only on those auctions using preferences, they do not utilize the variation in the preference policy across state funded and federal-aid auctions. As with this paper, they find that bid preferences increase the probability of small firms winning, however their simulations for mediumsized projects do not suggest a significant effect on procurement costs. Flambard and Perrigne (2006) estimate an asymmetric model of snow removal auctions by the city of Montreal, and provide counterfactual policy experiments suggesting that bid preferences could be used by the city to lower procurement costs by 16 percent. 
Ayres and Cramton (1996) provide a case study of the FCC auctions for the regional narrowband spectrum. For ten of the thirty auctions, minority and women owned enterprises were given bid preferences. On an additional ten auctions these firms were given more favorable payment terms. The authors provide evidence suggesting that non-favored firms bid more aggressively in the auctions for which preferences were employed, leading to higher revenues in those auctions. Consistent with participation concerns playing an important role, they find that bid preferences were set high enough in some auctions to discourage the entry of unfavored firms. Corns and Schotter (1999) provide evidence from a laboratory experiment using college students who were given varying bid preferences in hypothetical procurement auctions. They find that bid preferences lower the bids of non-preferred subjects while raising the bids of preferred subjects. Overall, procurement costs were lower under bid preferences.

Two other relevant papers examine the procurement cost effect of other forms of asymmetric treatment in procurement markets. Marion (2006) studies subcontractor utilization requirements for women and minority owned enterprises, finding significant reductions in government procurement costs due to California's Proposition 209. Denes (1997) examines contract set-asides, finding that restricting the bidding for federal dredging contracts to small businesses has little impact on the winning bid.

The paper proceeds as follows. Section 2 describes a model of bid preferences in an asymmetric auction model. Section 3 describes the preference program used by Caltrans and the data that will be used. The basic reduced form empirical results are presented in Section 4. In section 5, I display structural estimates of the model, and the results of the counterfactual simulations are shown. Section 6 concludes.

\section{Model}

In this section I present a model describing the effect of bid preferences on firms' bidding and participation decisions. Suppose the government wishes to purchase a road construction project through a first price sealed bid auction. There is a set of $N_{s}$ and $N_{l}$ potential small and large bidders, and each firm $i$ receives a private cost of entry into the auction, $K_{i}$, drawn from the distribution $H(K)$. Upon paying the fixed cost of entry, the firm learns its private cost of project completion, $c_{i}$, which is drawn from its type-specific distribution, $F_{\tau}$, where $\tau \in l, s .^{3}$

\footnotetext{
${ }^{3}$ Hong and Shum (2002) found that some categories of highway work exhibit characteristics suggesting they may have a common value component. The theoretical results of Harstad, Rothkopf, and Fu (2003) suggest that in a common value auction, bid preferences will have the effect of reducing the markup over cost of the unfavored firm while increasing the markup of the favored firm. They find that this may reduce expected procurement costs with an appropriately chosen bid preference level. Since these predictions match those of the private values model, I proceed by modeling costs as purely private values.
} 
Small firms need not submit the low bid to be awarded the contract. Large firm bids are adjusted up by $\theta$ when being compared to those of small firms, so that a small firm wins the auction provided $b_{s}<\theta \underline{b_{l}}$, where $\underline{b_{l}}$ represents the lowest large firm bid.

A type-symmetric equilibrium strategy will consist of a bid strategy $\phi_{\tau}\left(c ; n_{s}, n_{l}\right)$, and an entry threshold $K^{\tau}$. These strategies are formed in two stages. Conditional on entry, the firm chooses its bid to maximize expected profits, knowing the number of competitors and the distribution from which the competitors' costs are drawn. Bidders then make an entry decision based on whether their entry cost lies below their type-specific threshold.

Denote the equilibrium inverse bid function $c=y_{\tau}(b)$. A participating small business with cost $c$ has an expected profit of

$$
\pi=(b-c)\left(1-F_{s}\left(y_{s}(b)\right)\right)^{n_{s}-1}\left(1-F_{l}\left(y_{l}(b / \theta)\right)\right)^{n_{l}} .
$$

The large firm's objective function can similarly be written

$$
(b-c)\left(1-F_{s}\left(y_{s}(\theta b)\right)\right)^{n_{s}}\left(1-F_{l}\left(y_{l}(b)\right)\right)^{n_{l}-1} .
$$

The first order condition of $(1)$ with respect to $b$ reduces to

$$
c=b-\left(\left(n_{s}-1\right) \frac{f_{s}\left(y_{s}(b)\right) y_{s}^{\prime}(b)}{1-F_{s}\left(y_{s}(b)\right)}+n_{l} \frac{f_{l}\left(y_{l}(b / \theta)\right) y_{l}^{\prime}(b / \theta) / \theta}{1-F_{l}\left(y_{l}(b / \theta)\right)}\right)^{-1}
$$

with a similar first-order condition for the large firm:

$$
c=b-\left(n_{s} \frac{\theta f_{s}\left(y_{s}(\theta b)\right) y_{s}^{\prime}(\theta b)}{1-F_{s}\left(y_{s}(\theta b)\right)}+\left(n_{l}-1\right) \frac{f_{l}\left(y_{l}(b)\right) y_{l}^{\prime}(b)}{1-F_{l}\left(y_{l}(b)\right)}\right)^{-1}
$$

The solution to the system of differential equations described by (3) and (4), along with suitable boundary conditions, uniquely characterizes the equilibrium bid strategies. ${ }^{4}$

Firm $i$ 's expected profit from entry can be described by

$$
\Pi_{i}=\sum_{n_{s}, n_{l}} \int\left\{\pi\left(c ; n_{s}, n_{l}\right) d F_{i}(c)\right\} \operatorname{Pr}\left[n_{s}, n_{l} \mid K, i \in n\right]
$$

where $\operatorname{Pr}\left[n_{s}, n_{l} \mid K, i \in n\right]$ is the probability of observing the pair $\left(n_{s}, n_{l}\right)$ given that firm $i$ is a participant and competing firms use entry strategies $K$. The entry threshold is set such that $\Pi\left(K^{\tau}\right)=K^{\tau}$. Therefore, firms will enter provided their expected profit exceeds their entry cost.

The winning bid depends on $\theta$ directly through the switching mechanism that awards contracts to higher bidding firms, and indirectly through the strategic response of firms. Introducing bid

\footnotetext{
${ }^{4}$ The boundary conditions will be discussed in more detail in section 5
} 
preferences alters firms' equilibrium bid strategies by increasing the effective competition faced by large firms and reducing that faced by small firms. With a judiciously chosen level of bid preference, the competitive effect on the low cost firms can outweigh the effect on the higher cost firms. The second important effect of bid preferences is on the entry decision of firms. Lowering expected profits of large firms lowers their entry threshold $K^{l}$, making participation less likely. Conversely, the entry threshold of small firms is increased.

Represent the winning bid by $B\left(\theta, \phi_{\tau}\left(. ; \theta, n_{\tau}\right), n_{\tau}(\theta)\right)$, a function of $\theta$ and firms' type specific bidding and entry strategies, which both depend on the bid preference level. Comparing winning bids between preference and non-preference auctions will therefore incorporate the competing effects of bid preferences on firm markups and on the number of bidders. In the empirical specification of the winning bid, this comparison will be made conditional on project characteristics. By also conditioning on the level of participation $\left(n_{s}, n_{l}\right)$, it will be possible to isolate the effect of bid preferences on the winning bid through bid strategies and the switching mechanism.

With the information structure described by the model, entry will be orthogonal to the firm's ex post cost of completing the project. However, if the model is extended to allow firms to receive a signal of their construction cost prior to paying the entry cost, it will lead the cost distribution of observed participants to depend on $\theta$. To illustrate this, assume for simplicity that a firm receives a private cost signal that takes on one of two values, $c^{H}$ or $c^{L}$, which indicates whether a firm is below or above the expected cost for a firm of type $\tau$. As before, the firm then learns its true cost upon paying the entry cost. This leads to two different entry cost thresholds within type, $K_{H}^{\tau}<K_{L}^{\tau}$. Here, a firm's entry decision is no longer orthogonal to its eventual project completion cost, as firms receiving the low-cost signal are more likely to enter. The cost distribution of participants will differ from the distribution of the broader population of firms.

This could introduce another channel through which bid preferences effect the winning bid. Bid preferences reduce markups for large firms and raise markups for small firms, and the size of this effect will depend on the cost of the firm. Therefore, bid preferences may change the entry thresholds $K_{H}^{\tau}$ and $K_{L}^{\tau}$ by different amounts, and this will alter the distribution of participants. Suppose the cost distribution of participants of type $\tau$ is given by $\widetilde{F_{\tau}}$, and this depends on $\theta$. The winning bid can then be represented by $B\left(\theta, \phi_{\tau}\left(. ; \theta, n_{\tau}\right), n_{\tau}(\theta), \widetilde{F_{\tau}}(\theta)\right)$. As a result, the comparison of winning bids between preference and non-preference auctions may also incorporate the effect of bid preferences on the observed distribution of participants. 


\section{Data and Background}

\subsection{Bidding on California Highway Auctions}

Caltrans awards road construction and repair contracts through sealed-bid first-price auctions. Potential bidders are solicited through a newsletter that details the bid letting date and the details of the project. A firm can bid on any project for which it has been prequalified to do the specified category of work; this prequalification is based on the firm's equipment, training, licensing, and past work history. A firm specifies in its bid which subcontractors it will use and a unit price of each item the engineer has specified. ${ }^{5}$

Small businesses are given a bid preference on all contracts not using federal funds. If a small bidder bids within a certain dollar amount of the lowest regular bidder, the small business is awarded the contract. The preference amount is either 5 percent of the lowest large firm bid or $\$ 50,000$, whichever is less.

A firm must meet several criteria to qualify as a small business. The firm must be independently owned and operated, so that larger firms are not able to form smaller subsidiaries to take advantage of the program. The firm must be located in California, have less than 100 employees, and have earned less than $\$ 10$ million in average annual revenue in the past three years.

Caltrans also implements an affirmative action program for firms owned by minorities and women. This program requires prime contractors to subcontract a specified portion of a project to disadvantaged business enterprises (DBEs). This program was ended in 1998 for projects using only state funds, however it was continued for projects using federal aid throughout the time period considered here. The Caltrans office indicates that few DBEs bid as prime contractors, and for the majority of the sample even a DBE prime contractor was required to hire enough minority and women owned subcontractors to meet the DBE goal.

\subsection{Federal aid for highway projects}

The U.S. Department of Transportation provides funds to states for the maintenance and construction of interstate and national highways, bridge projects, air quality and congestion management efforts, and other local projects. Federal aid for highway projects is funded through user related

\footnotetext{
${ }^{5}$ Preferences are also given to firms of any size located in the state of California when bidding against out-of-state firms. The program is reciprocal in that preferences are only considered when the California firm is competing against a firm originating from a state with a local preference program. In that case, the preference given to the California firm is equal to the preference that would be given to the competing firm in its own home state. Aside from California, only sixteen states operate some sort of preference program for local firms. Of these sixteen states, ten are reciprocal programs like California, and only six states set a preference parameter. In the data for California roadway auctions, no bids are observed by firms with home offices in one of those six states.
} 
taxes such as gasoline taxes and truck-related taxes. A state's share of the federal funds through this program is related to a state's contributions to the Highway Trust Fund. ${ }^{6}$

A federal apportionment formula determines the grant to be given to the state under each federal aid program in a given year. While there is a fair amount of discretion as to what projects qualify for aid, there are specific formulas determining the percentage of a project's costs that are used for federal aid. For instance, for a project funded under the national highway system program, federal funds account for 90 percent of the project's costs. Therefore, it is not possible for the state to apply a small amount of federal aid to all projects.

\subsection{Data}

The data in this study consist of information for 4,136 highway construction contracts awarded by Caltrans between May 1996 and December 2002. For each awarded contract, a set of information describing the project is given, including the road and county where the work will take place; a short description of the nature of work to be completed; and the estimated number of working days to complete the project. The federal-aid status of the contract is given as well as the project specific DBE participation requirement. Each submitted bid is observed, including the bidder's location and a list of subcontractors the firm will use.

Caltrans specifies each item that will be required to complete a project and the quantity of that item to be used. The bidder places a unit price for each item, and the sum of the unit prices multiplied by their quantities gives the total bid: $\sum_{j} p_{i j} q_{i j}=B_{i}$. The unit prices are used in the event that more of a particular item is required to complete the project, in which case the contractor is allowed extra compensation given by the unit price multiplied by the unexpected quantity. Also, the engineer's office uses the item prices to generate highway construction cost indices for common categories of items. These cost indices, along with project specific factors, are used to form an engineer's estimate of the cost of completing each project.

The data is somewhat limited in identifying firms that qualify as small business bidders. Data describing revenue and employees, the two main criteria by which small business status is evaluated, are unavailable. As a result, small business status must be inferred from whether a firm claims the small business preference when bidding on state funded auctions. One complication is that the

\footnotetext{
${ }^{6}$ Prior to 2000, a state's disbursements were determined by long range estimates of its contributions to the Highway Trust Fund. After 1999, there was a substantial increase in the amount of federal funding allocated to California as a result of the Revenue Aligned Budget Authority. The RABA tied disbursements to actual tax revenue, which increased dramatically during the expansion years. As a result of this increase, the average federal-aid project increased dramatically in size. The results obtained later in the paper are robust to the exclusion of post-1999 contracts.
} 
same firm does not always bid as a small business. The 421 firms that bid at least once as a small business do so 67.3 percent of the time on preference auctions.

A likely explanation is that some smaller firms temporarily fail to meet either the revenue requirement, the number of employees requirement, or both. ${ }^{7}$ A firm engaged in other work may increase its workforce above the 100 employee limit. Also, the government typically makes progress payments to contractors while projects are underway, which could increase a firm's average revenue above the $\$ 10$ million threshold. Jofre-Bonet and Pesendorfer (2003) find that capacity constraints are important in the road construction industry, suggesting that a given firm could face different marginal costs when bidding as a small business than when bidding as a large business.

The possibility that capacity constraints are correlated with small business status is supported by the relationship between past contract volume and the propensity of firms to claim small business status. Consider firms that bid as a small bidder at least once. Summing the volume of contracts a firm has won over the previous three years yields a measure that should be correlated with total firm revenues as long as firms do not excessively substitute away from non-Caltrans road projects when a Caltrans contract is won. In Figure 1, the propensity of firms to bid as a small business is plotted by total contract volume in the past three years. Among firms that ever bid as a small business, the propensity to claim small business status is greater than 70 percent when total past volume is less than $\$ 10$ million and between $\$ 10$ and $\$ 20$ million. When past volume is greater than $\$ 20$ million, firms bid as small bidders less than 25 percent of the time.

A potentially strong relationship between claimed small business status and firm costs could therefore exist. This is particularly problematic since small business status is not known on nonpreference auctions. The empirical work will define a firm as a small business if it ever bid as one on a preference auction. While this measure will avoid bias associated with endogenous small business status, it will potentially understate the effect of bid preferences on the bids of small firms since it is an imperfect measure of small business status.

\section{SUMMARY STATISTICS}

Table 1 presents the summary statistics of the data. Panel A shows the average characteristics for all projects, while Panel B shows only projects where the engineer's estimate is less than $\$ 1$ million. Projects using federal aid tend to be larger in size. The median engineer's estimate on federal aid projects is $\$ 1.34$ million, nearly four times the median engineer's estimate of $\$ 0.35$

\footnotetext{
${ }^{7}$ Another candidate is that firms are graduating from the small business program. The data, however, indicate this is unlikely. There are 227 firms that only sometimes bid as a small bidder. These firms bid as a small bidder 60 percent of the time on the final auction that they bid on in the data, which is not significantly different from the rate for all auctions.
} 
million for state funded projects. Small firms make up a greater proportion of the bidders on state funded contracts than they do on the non-preference federal aid projects, and much of this difference is due to differences in size between the two types of projects.

Small firms are more likely to win preference auctions than non-preference auctions. On average, 2.33 small bidders participate in federal aid projects under $\$ 1$ million compared to 3.66 large participants (t-statistic of difference=11.87). While small firms represent 39 percent of the bidders in non-preference auctions, this proportion grows to 46 percent of bidders in preference auctions, where 2.42 small bidders participate compared to 2.89 large firms (t-statistic=6.49). Based on the summary statistics, bid preferences seem successful at levelling the playing field. The average small bid has a 14.5 percent chance of winning a non-preference auction, 4.1 percent lower than the average large bid (t-statistic $=3.68)$. On preference auctions, small firms are only 0.4 percent less likely to win (t-statistic=0.54), with the average small bid winning 18.8 percent of the time compared to 19.2 percent for large firm bids. Some of this improvement can be directly accounted for by the use of preferences, which were invoked on 7 percent of the eligible auctions. It is important to note that due to the competitive response of small and large firms, it is not necessarily true that in each of these cases the winner would have been different had the auction been conducted without preferences.

Despite differing in size, state funded and federal aid contracts are similar in other dimensions. For smaller projects work takes place on state highways for 64 percent of the state funded projects compared with 70 percent of the federal aid contracts. Interstates account for 8 percent of both state and federally funded contracts. The proportions are also similar for U.S. highways and other types of roads as well. The types of projects are also similar across the two types of auctions. By far, the most common type of project involves road construction and repair, as 52 percent of state funded contracts primarily involve this type of work compared with 53 percent for federal aid contracts. There are several other types of projects, including bridge construction and repair, landscaping, and drainage. There are no noticeable differences between state funded and federal aid contracts in the composition of these projects either.

\section{Reduced form results}

\subsection{Procurement Cost Effect}

This section describes a simple empirical approach that uses the distinction between state funded and federal aid projects to identify the effect of bid preferences on government procurement costs. 
Suppose the log of the winning bid, $\ln (B)$ on auction $k$ is a function of the preference format used and a set of project specific characteristics: ${ }^{8}$

$$
\ln \left(B_{k}\right)=\beta_{0}+\beta_{1} * \text { PREFAUCTION } N_{k}+\beta^{\prime} X_{k}+\epsilon_{k} .
$$

The sample considered are those projects where the engineer's estimate is less than $\$ 1$ million. Bid preferences are proportionally the same for these projects, since the bid preference is capped at $\$ 50,000 .^{9}$ For larger projects, the importance of preferences depends on the scale of the project, which is likely correlated in an unknown way with the distribution of small firm costs. ${ }^{10}$

Two other key aspects of this model must be noted. First, the equation (6) will be estimated with and without including the number of bidders in the vector $X_{k}$. Excluding the number of bidders allows the coefficient $\beta_{1}$ to incorporate the correlation between the preference format used and firm participation. Second, this model only identifies $\beta_{1}$ if there are no unobserved components of $X_{k}$ correlated with PREF AUCTION. Included in $X_{k}$ will be the engineer's estimate, number of workdays, number of items to be provided, the minority subcontractor participation goal, indicators for broad work categories, as well as road, county, year, and month effects. ${ }^{11,12}$

The results of this specification are shown in Table 2. Column (1) displays the results from estimating (6) without controlling the number of small and large bidders. The winning bid is found to be 3.8 percent higher on preference auctions than on similar non-preference auctions (p-value $=0.002)$. The specification shown in column (2) controls for the number of bidders by including variables indicating the number of small and large bidders. Including these controls reduces the coefficient on the preference auction dummy to 0.020 ( $\mathrm{p}$-value $=0.099)$, suggesting that approximately half of the procurement cost effect of preferences is due to fewer bidders participating on preference auctions.

Finally, column (3) displays results controlling for firm fixed effects, which is meant to control for the composition of winners on preference versus non-preference auctions. Including firm effects

\footnotetext{
${ }^{8}$ If the relative cost of small and large firms differs by project size, then the effect of preferences could be correlated with project size as well. Estimating a model of the log bid could be misleading since it gives proportionally greater weight to smaller values of the dependent variable. However, estimating similar specifications in levels rather than yields similar results.

${ }^{9}$ The engineer's estimate is used as the cutoff rather than the lowest firm bid since this is a choice variable of the firm, which would make the cutoff correlated with the preference regime.

${ }^{10}$ In addition to this problem, as project size gets larger, the number of observed state funded (preference) auctions declines dramatically. This makes inference difficult as the estimated effects are very imprecise.

${ }^{11}$ Marion(2005) shows that the minority participation requirement could impact firm costs. This requirement was lifted on state funded contracts as a result of Proposition 209 in March 1998. Controlling for the requirement percentage is meant to account for the differential effect of Prop. 209 on state funded contracts.

${ }^{12}$ Athey, Levin, and Seira (2004) employ two methods for controlling for observable heterogeneity. They run a logit of auction form on covariates, and then drop observations with particularly high or low propensity scores. They also use a matching estimator. Both of these methods yield qualitatively similar results to those presented in this paper.
} 
reduces the coefficient on the preference auction variable to -0.005 and is indistinguishable from zero (p-value $=0.681)$. Two explanations could account for the weaker composition of winners. First, preferences sometimes shift the project from the low bidder to a higher bidding small firm. However, preferences are invoked on only 7 percent of the preference auctions, so the most this could increase the winning bid is 0.3 percent -7 percent multiplied by 5 percent, the highest possible value of the bid preference. Second, as discussed in theoretical model, another explanation could be that the set of auction participants have a different distribution of costs on preference versus non-preference auctions. I consider this possibility in more detail in Section 4.3.

\subsection{Bidding behavior}

Conditional on auction participation, to what extent are firms responding to the use of bid preferences? Bid preferences can only lead to a fall in procurement costs if they lead large firms to bid more aggressively. Even if large firms bid more aggressively, if small firms respond by bidding more passively then the net effect of preferences on government costs could be positive.

This section models the log of the firm's bid as a linear function of a small business indicator, a preference auction indicator, and an interaction between these two. Again, a set of auction specific covariates are employed to control for factors that shift costs across projects, and only projects where ENGEST < $\$ 1$ million are considered. The equation to be estimated is as follows:

$$
\ln \left(b_{i k}\right)=\beta_{0}+\beta_{1} S B_{i} * P R E F_{k}+\beta_{2} S B_{i}+\beta_{3} P R E F_{k}+B^{\prime} X_{i k}+\eta_{i}+\alpha_{k}+\epsilon_{i k}
$$

where $S B_{i}$ is a small business indicator variable and $P R E F_{k}$ is an indicator for whether auction $k$ uses preferences. Each specification will include in $X_{i k}$ the $\log$ of the engineer's estimate, $\ln (E N G E S T)$, and dummy variables for each interaction of the number of small and large bidders.

Together, the estimates of $\beta_{1}$ and $\beta_{3}$ can be used to infer the effect of preferences on the behavior of small and large firms. The coefficient $\beta_{3}$ represents the extent to which large firms lower their bid in response to preferences. For small firms (where $S B=1$ ), the coefficient on the preference auction dummy is $\beta_{1}+\beta_{3}$.

Some specifications will control for firm effects, $\eta_{i}$, which account for the different participation patterns observed by small and large firms. If relatively strong large firms participate less often when preferences are used, then the coefficient $\beta_{3}$ will be biased upward. If some firms tend to be consistently weak or strong across auctions, then controlling for firm fixed effects will account for changes in the composition of auction participants. 
Finally, even for projects where the engineer's estimate is less than $\$ 1$ million, the average preference auction is smaller than the average non-preference auction. Included in $X_{k}$ will be a control for an interaction between the small business indicator and the engineer's estimate normalized by its mean, $\ln \left(\widetilde{E G E} S T_{k}\right)$, to account for the effect of project scale on small firm costs. One specification will also include contract effects, $\alpha_{k}$, which will control for the participation of firms without having to control for the potentially endogenously determined number of bidders. Doing so will not allow the estimation of the coefficient $\beta_{3}$, only the relative effect of preferences on small versus large firms.

Table 3 displays the estimates of (7). A necessary condition for preferences to reduce procurement costs is that unfavored firms be cost advantaged relative to small firms. The coefficient on the small business indicator variable is 0.016 and statistically significant, suggesting that large firms do have a small advantage in costs. It is worth noting that low cost firms markup bids over costs more than high cost firms, indicating that this estimate represents a lower bound of the difference in costs between the average small and large firm.

For the full set of bidders, the impact of preferences on bids is estimated to be quite small. The average large firm bids approximately the same on preference auctions, while the average small firm bids higher by a statistically insignificant 1.1 percent ( $\mathrm{p}$-value=0.21). Due to the elimination of affirmative action for state funded contracts in 1998, preference auctions have a lower mean DBE goal than the non-preference auctions. Controlling for the goal will be insufficient if it has a differential impact on small and large firms. The specification in the second column accounts for this possibility by controlling for the interaction between the small business indicator and the DBE goal on the project. The inclusion of this control has little effect on the estimated coefficients.

The results presented in column (3) include controls for firm effects to account for the potentially different composition of bidders between preference and non-preference auctions. The results show that the difference between the bids of small and large firms on preference auctions is 1.5 percent higher than the difference on non-preference auctions $(p$-value $=0.094)$, indicating a small but detectable effect of preferences on bid strategies. ${ }^{13}$ Unfortunately the imprecision with which the coefficient on the preference auction variable is estimated does not allow for reliable conclusions to be drawn regarding whether the response is through lower bids by large firms or higher bids by small firms. Column (4) contains the results from the specification employing contract fixed effects,

\footnotetext{
${ }^{13}$ The effect of preferences on small firms may be understated due to the use of a proxy variable for small business status. Since the variable employed describes firms that ever bid as a small business, it will sometimes take on a value of one when the true value is zero but never take on a value of zero when the true value is one.
} 
which may be preferable to controlling for the endogenously determined level of participation. Including this control leads to an estimate of the increase in the difference between small and large firms of 0.8 percent $(\mathrm{p}$-value $=0.311)$ in preference auctions.

\section{ONLY TOP BIDDERS}

While the specifications considering the full set of bids presented in columns (1)-(4) generally conform with predicted behavior, they imply a relatively modest strategic response of firms to bid preferences that is imprecisely estimated. By considering all bids, these specifications assume that the effect of preferences is constant throughout the cost distribution. However, firms receiving a high cost draw likely bid close to costs, which leaves little room for a strategic response to bid preferences. Therefore, the effect of bid preferences should be largest in the lowest cost firms, as they earn the largest information rents. Furthermore, the equilibrium winning bid is not highly sensitive to the bids of firms higher in the cost distribution. To assess the role of firms' bidding response to preferences in procurement costs, the behavior of the lowest cost firms will be most relevant.

The specifications shown in columns (5)-(8) of Table 3 only consider the bids of the top small and large bidders. According to auction theory, the equilibrium bid function is monotonically increasing in cost. These firms should therefore have the lowest within-type cost on a particular auction. As expected, the strategic effect is considerably larger when considering only the lowest cost firms. Without firm effects, the estimated difference between small and large firms is 2.6 percent $(p$-value $=0.024)$. This result is robust to the inclusion of firm and contract effects, as well as the SB*DBE Goal interaction term. The estimated effect of preferences on the bids of large firms conditional on firm effects is estimated to be -1.0 percent, which is of the predicted sign yet imprecisely estimated ( $\mathrm{p}$-value $=0.413$ ). Finally, column (8) displays the results of the specification including contract level fixed effects. This leads to a coefficient on the preference auction*small business interaction term of 0.034 ( $\mathrm{p}$-value $=0.041)$, which is slightly larger than the other estimated coefficients.

\subsection{Participation}

Participation patterns could lead to a higher equilibrium winning bid if fewer firms participate in preference auctions, or if the set of participants have higher costs. This section examines the participation margin more closely, finding a consistent pattern of weaker large firm participation on preference auctions. ${ }^{14}$

\footnotetext{
${ }^{14}$ Reservation prices could be one source of variation in participation across auctions. Caltrans uses reservation prices in its auctions, however these are only sometimes binding. In a significant proportion of the cases where all bids are above the reservation price, the Caltrans seeks and receives additional funding from the state, and subsequently awards the contract to the low bidder. This observation, coupled with the fact that bids are often observed well in excess of the reservation price, leads me to ignore it in the reduced form and structural estimation.
} 
The goal of this section is to establish the effect of preferences on the number of bidders. Table 4 presents results from regressing the number of small and large bidders on a bid preference dummy. Without controlling for any auction characteristics, the mean number of small bidders on preference and non-preference auctions is similar. The coefficient on the preference indicator is 0.08 ( $\mathrm{p}$-value $=0.365$ ), and after controlling for observable auction characteristics the coefficient on the preference indicator is -0.12 ( $\mathrm{p}$-value=0.391). Conversely, the number of large bidders is significantly lower in bid preference auctions. Preference auctions see 0.74 fewer large bidders than non-preference auctions. Some of this difference is accounted for by the characteristics of preference auctions. Since preference auctions tend to be smaller, they may attract fewer large firms. Even after accounting for auction covariates, the estimated effect of bid preferences is a reduction of 0.49 large firms ( $\mathrm{p}$-value $=0.001$ ). This represents 14 percent of the mean number of large bidders.

To what extent does the participation effect merely reflect substitution between preference and non-preference auctions by large bidders? To answer this question, I treat upcoming projects as potential substitutes for a firm and consider how the mix between state and federally funded projects alters firm participation decisions. As shown by Jofre-Bonet and Pesendorfer (2003), firm distance from a project and the number of plants the firm has nearby are significant determinants of the bidder participation decision, suggesting that firms do not view far away projects as close substitutes to nearby projects. Also, projects are advertised with a four to ten week lead time. These two facts lead me to measure the expected number of substitute projects as the number of upcoming projects with a bid opening in the next six weeks and inside the project's Caltrans district. $^{15}$ To determine the degree to which substitution is affecting the participation results, I interact the fraction of upcoming projects that are preference auctions with the preference auction dummy variable. As the fraction of upcoming auctions using preference goes to one, it approximates the counterfactual setting where all auctions are conducted with bid preferences.

Columns (3) and (6) of Table 4 present the results of this estimation. We see that more upcoming auctions reduce the participation of firms in the current auction, reinforcing the claim made by Jofre-Bonet and Pesendorfer that firms take into account the effect of future capacity constraints on current decisions. For small firms, I fail to find a statistically significant effect of the mix of upcoming auctions on participation. However, for large firms the mix of future auctions has a significant effect on current participation. I find that -0.821 fewer large firms show up to a

\footnotetext{
${ }^{15}$ The results turn out to be robust to expanding the definition of the geographic market to include the neighboring district, and adjusting the time period of relevant future auctions between 4 and 10 weeks or to reflect the number of working days (and therefore the anticipated effect of the current project on backlog).
} 
preference auction when no upcoming auctions utilize preferences. As the fraction of future auctions using preferences increases, the adverse participation effect of bid preferences is ameliorated. For every 10 percentage point increase in the preference auction prevalence, the effect of bid preferences on participation is reduced by 0.064 firms. If all upcoming auctions use preferences, then these two coefficients imply that -0.184 fewer large firms would participate in a preference auction.

\section{PARTICIPATION AND THE QUALITY OF PARTICIPANTS}

How does the the average quality of bidders compare on preference versus non-preference auctions? Recall from section 4.2 that including firm effects when estimating (7) has a notable effect on the estimated impact of preferences on bidding behavior. Changes in the participation patterns of firms from different locations in the cost distribution could be one explanation. Consider the estimates of the firm fixed effects, $\eta_{i}$ in equation (7). Define a low cost small firm as one whose $\eta_{i}$ is below the small firm median and define a low cost large firm similarly. Table 5 presents the mean number of high-cost and low-cost large and small participants. Preference auctions effect the participation of low cost large firms the most. The average preference auction has 1.43 low cost large bidders compared with 1.92 for the typical non-preference auction. High cost large firms are also affected, but to a smaller degree. There are 0.24 fewer high cost large firms on preference auctions. The participation of small firms seems unaffected. Preference auctions see 0.02 more low cost small firms than non-preference auctions and 0.07 more high cost small firms.

\section{$5 \quad$ Structural Estimation and Efficiency}

Underlying the changes in procurement cost documented in the previous section is a shift in economic efficiency. Preferences affect both markup over cost as well the cost of the winning bidder, yet the reduced form approach is able to uncover only the effect on bids and not the efficiency loss associated with preferences. ${ }^{16}$ Furthermore, it does not allow for evaluation of other levels of the bid preference parameter.

This section employs a structural model to study how efficiency, defined as the construction cost of the winning firm, is affected by the use of preferences. In the auction literature, efficiency loss is typically described by the difference between the lowest cost of the auction participants and the cost of the winning bidder. Extending this definition to include the effect of participation on the construction cost of the winning firm is appropriate if bid preferences alter expected profits

\footnotetext{
${ }^{16}$ Rezende (2004b) shows how OLS regressions similar to that presented in table 2 can be used to estimate the impact of covariates on firm valuations. However this methodology is potentially less powerful in settings with asymmetric auctions, where it will not uncover the distribution of valuations of the different classes of firms.
} 
and not the distribution of participation costs. In the reduced form section, I documented reduced participation of large firms on preference auctions. Assuming participation costs are the same across the two formats, if bid preferences lower the entry cost threshold for a firm, then a loss in efficiency results since the expected cost of the winning bidder is now higher.

One strong assumption of the expanded definition of efficiency is also worth noting. This definition assumes that the participation decision of a firm on one auction does not impact its participation decision on other auctions. However, if preferences lead a large firm to participate not only in fewer preference auctions but also in more non-preference auctions, then the higher expected construction cost in one is offset by lower expected costs in the other. The definition of efficiency loss used in this paper may therefore overstate the efficiency loss due to participation.

Evaluating changes in construction costs associated with bid preferences requires estimates of unobserved firm costs. This section will estimate the bidding stage of the model of bid preferences presented in section 2 using the nonparametric techniques of Guerre, Perrigne, and Vuong (2000) to obtain the latent costs of firms. These costs can be used to calculate firm profits, as well as the construction cost of the winning bidder on preference and non-preference auctions. Furthermore, the distribution of costs of participants on non-preference auctions can be used to simulate a counterfactual set of preference auctions holding participation fixed. Therefore, the effect of preferences on the construction cost of the winning bidder can be assessed, and this effect can be divided between the direct effect of preferences (altering the winning bidder given a set of participants) and the indirect effect working through participation. ${ }^{17}$

\subsection{Structural Estimation of Private Costs}

Structural estimation uncovers the set of firm costs that rationalizes the set of observed bids, assuming that the observed bids represent a Bayes Nash equilibrium. Under this assumption, the firm's latent costs can be inferred using the firm's first-order conditions from (3) and (4). Since $b, n_{s}, n_{l}$, and $\theta$ are known, structural estimation proceeds by obtaining estimates of the other unknown elements of these equations. Since project characteristics vary across auctions, the distributions to be estimated are indexed by $k$. Let $G_{\tau k}(b)$ be the distribution of bids for firms of type $\tau$ on auction $k$, and let $g_{\tau k}(b)$ be its associated density. The monotonicity of $y_{\tau k}(b)$ implies

\footnotetext{
${ }^{17}$ The distribution of firms on federal aid contracts could be a poor counterfactual for the distribution of state funded participants if the substitution of large firms out of preference auctions and into non-preference auctions is correlated with firm costs. However, using the fraction of upcoming contracts that use preferences as a measure of the outside substitution opportunities, I do not find important differences between the distribution of costs when there are substitution opportunities versus when there are not.
} 
that $G_{\tau k}(b)=F_{\tau k}\left(y_{\tau k}(b)\right)$ and $g_{\tau k}(b)=f_{\tau k}\left(y_{\tau k}(b)\right) y_{\tau k}^{\prime}(b)$. Therefore, given suitable estimates of $g_{\tau k}$ and $G_{\tau k}, \widehat{g_{\tau k}}(b)$ and $\widehat{G_{\tau k}}(b)$, each small bidder's latent costs from (3) can be estimated from

$$
c=b-\left(\left(n_{s}-1\right) \frac{\widehat{g_{s k}}(b)}{1-\widehat{G_{s k}}(b)}+n_{l} \frac{\widehat{g_{l k}}(b / \theta) \frac{1}{\theta}}{1-\widehat{G_{l}}(b / \theta)}\right)^{-1}
$$

and the latent costs of large firms from

$$
c=b-\left(n_{s} \frac{\theta \widehat{g_{s k}}(\theta b)}{1-\widehat{G_{s k}}(\theta b)}+\left(n_{l}-1\right) \frac{\widehat{g_{l k}}(b)}{1-\widehat{G_{l}}(b)}\right)^{-1} .
$$

Since bids submitted under one combination of small and large bidders are not comparable with bids submitted under another $\left(n_{s}, n_{l}\right)$ combination, nor are bids submitted under auctions with preferences comparable with bids submitted under auctions without preferences, then $G_{i k}(b)$ and $g_{i k}(b)$ must be estimated separately for each $\left(n_{s}, n_{l}\right)$ and for each $\theta$.

Table 6 shows the number of bid observations at each $\left(n_{s}, n_{l}\right)$ combination for preference $(\theta=1.05)$ and non-preference $(\theta=1.0)$ auctions. At many points in this matrix, there are very few observations with which to estimate the relevant distributions. Haile et al (2003) estimate those auctions for which they have greater than approximately 75 observations. Here, I will estimate the model for auctions with between two and five large bidders and between one and four small bidders. The results are qualitatively similar when this is expanded to include more auctions. While the estimation method employed here yields consistent estimates, as Guerre, Perrigne, and Vuong (2000) note, the estimated distribution $\hat{g}(b \mid z)$ only converges at the rate $(n L)^{1 / 6}$, where $n L$ is the number of bid observations across all auctions. Thus, the nonparametric estimator requires a relatively large number of observations, which should be kept in mind when interpreting the results.

This estimation method assumes that the number of bidders is exogenously given, which in this setting will lead to a biased estimate of the underlying distribution from which costs are drawn. This method is able to identify only the distribution of auction participants. This significantly limits the counterfactual exercises that can be considered, since participation is not modeled explicitly and estimates of the distribution of all potential bidders are not derived.

\subsubsection{Project heterogeneity}

Structural estimates of costs will be biased without controlling for project specific cost shifters. The bias enters through two channels. First, estimated costs will be biased downward on less complex projects and biased upwards on more complex projects. Since project size is correlated with the federal-aid status of the project, profits will be overstated for state funded projects. Second, 
unobserved heterogeneity spreads out the distribution of bids. This biases downward the estimate of the density $g(b)$ for a given bid, which leads to a downward bias in estimated firm costs.

While the first bias is obviously a problem when comparing preference and non-preference auctions, the second bias could be important as well. The impact of bid preferences on procurement costs works through the tradeoff between reducing the profits of large firms and awarding more contracts to higher cost firms. The evaluation of this tradeoff could be particularly sensitive to biases in the estimation of firm costs.

This paper uses the approach taken by Flambard and Perrigne (2006) and Elyakime et al (1994) who allow the distribution $F_{\tau k}(c)$ to depend on auction characteristics, $z_{k}$, such that $F_{\tau k}(c)=$ $F_{\tau}\left(c \mid z_{k}\right){ }^{18}$ Due to data requirements, $z_{k}$ is typically measured as a single variable. Elyakime et al (1994) for instance study auctions of timber lots and use the estimated percentage of saw timber of the lot. The approach taken here will condition on the engineer's estimate.

The conditional distribution method has several advantages in the context of estimation of auctions with bid preferences. First, it does not require the value of bids to be adjusted as in Haile, Hong, and Shum (2003). In that case, the value of the bid preference applied to the conditional bid does not match the value applied on the original auction since the bid preferences in the California program are stated as a percentage of the bid. Second, the distribution of costs of small and large firms is allowed to vary in an arbitrary way depending on the scale of the auction. This is important since large firms may bid less aggressively on larger projects knowing they face less competition from smaller firms.

\subsection{Estimation method and results}

The estimation of the elements of $(8)$ and $(9), \widehat{g_{\tau}}(b \mid z)$ and $\widehat{G_{\tau}}(b \mid z)$, are obtained from observed bids using standard kernel techniques. Note that the conditional distributions are related to the joint distribution of $b$ and $z$ through $\widehat{g_{\tau}}(b \mid z)=\widehat{g_{\tau}}(b, z) / f_{z}(z)$ and $\widehat{G_{\tau}}(b \mid z)=\widehat{G_{\tau}}(b, z) / f_{z}(z)$, where $\widehat{f}_{z}(z)$ is the density of the engineer's estimate. The following nonparametric estimators are used to obtain the joint distributions of $b$ and $z$, and density of $z$ :

$$
\begin{gathered}
\widehat{g_{\tau}}(b, z)=\frac{1}{K h_{g}^{2}} \sum_{k=1}^{K} \frac{1}{n_{\tau k}} \sum_{p=1}^{n_{\tau k}} K_{g}\left(\frac{b-b_{\tau p k}}{h_{g}}, \frac{z-z_{k}}{h_{g}}\right) \\
\widehat{G_{\tau}}(b, z)=\frac{1}{K h_{G}} \sum_{k=1}^{K} \frac{1}{n_{i k}} \sum_{p=1}^{n_{\tau k}} 1 I\left(b_{\tau p k} \leq b\right) K_{G}\left(\frac{z-z_{k}}{h_{G}}\right)
\end{gathered}
$$

\footnotetext{
${ }^{18}$ For alternative methods of accounting for heterogeneity in auction estimation, see Krasnokutskaya (2002), Athey, Levin, and Seira (2004), and Haile, Hong, and Shum (2003).
} 


$$
\widehat{f}_{z}(z)=\frac{1}{h_{z} K} \sum_{k=1}^{K} K_{z}\left(\frac{z-z_{k}}{h_{z}}\right) .
$$

According to the conditions provided by Guerre et al. (2000), the chosen kernel must have compact support and be continuously differentiable on its support, including the boundaries. Following Li, Perrigne, and Vuong (2000), I will use the triweight kernel

$$
K(u)=\frac{35}{32}\left(1-u^{2}\right)^{3} 1(|u| \leq 1)
$$

The kernel for the estimation of the joint density $\widehat{g_{\tau}}(b, z), K_{g}$, is the product of two triweight kernels. The choice of kernel does not have a quantitatively important impact on the results. The use of the biweight kernel for instance yields similar estimated distributions. However, the results are somewhat sensitive to the choice of bandwidth. It is common practice to use the rule of thumb suggested by Hardle (1991), which sets the bandwidth according to $h_{g}=c_{g} * 1.06 * \hat{\sigma}(n L)^{-1 / 6}$, where $c_{g}$ is a constant and $\hat{\sigma}$ is the standard deviation of the underlying data.

As Hardle notes, the rule of thumb bandwidth is optimal only if the kernel resembles the true distribution of underlying data. Yet observed bids are skewed significantly to the right, while commonly used kernels tend to be symmetric. The skewness of the bids is illustrated in figure 2 , which plots kernel estimates of the density of the bid relative to the engineer's estimate. The density of bid/estimate is skewed due to outliers in the right tail of the distribution, however when considering the log difference between bids and engineer estimates the distribution appears symmetric.

To reduce the effects of skewness, I consider the commonly used log transformation of bids (see for instance Li et al, 2000). In this case, equation (8) becomes

$$
c=\exp (a)\left(1-\left(\left(n_{s}-1\right) \frac{\widehat{g_{s k}^{a}}(a)}{1-\widehat{G_{s k}^{a}}(a)}+n_{l} \frac{\widehat{g_{l k}^{a}}(a-\log (\theta)) \frac{1}{\theta}}{1-\widehat{G_{l k}^{a}}(a-\log (\theta))}\right)^{-1}\right)
$$

where $a=\log (b), \widehat{G_{\tau k}^{a}}$ is the estimated distribution of $a$ for a bidder of type $\tau$ in auction $k$, and $\widehat{g_{\tau k}^{a}}$ is the associated density. Similarly, the cost of the large firm can be obtained from the analog of (9),

$$
c=\exp (a)\left(1-\left(n_{s} \frac{\widehat{\theta g_{s k}^{a}}(a+\log (\theta))}{1-\widehat{G_{s k}^{a}}(a+\log (\theta))}+\left(n_{l}-1\right) \frac{\widehat{g_{l k}^{a}}(a)}{1-\widehat{G_{l k}^{a}}(a)}\right)^{-1}\right)
$$

Estimation of the components of (14) and (15) must be performed separately for preference and non-preference auctions and for each combination of the number of small and large bidders, 
since the inverse equilibrium strategy is conditional on the preference parameter and the number of bidders.

Figures 3 and 4 display kernel estimates of the cost distributions for small and large participants on non-preference and preference auctions, evaluated at the median of the engineer's estimate. In auctions without preferences, the distribution of large firms dominates that of the small firms. For auctions with preferences, however, the estimated cost distribution of small and large participants are very similar except for very low cost values. This is a very striking pattern of participation. Consistent with the reduced form results, the reduced participation of stronger large firms on preference auctions is largely responsible.

\section{IS POOLING ACROSS PARTICIPATION LEVELS APPROPRIATE?}

The estimation strategy implemented above pools different levels of participation (different $n_{s}$ and $n_{l}$ ) when estimating the distribution of costs. However, such pooling is inappropriate if the participation decision is endogenously related to firm costs, and if this leads to different cost distributions depending on the number of bidders. To evaluate the extent of this problem, I estimate the cost distributions separately for different levels of participation, and I assess the degree to which this depends on the scale of the project. I consider relatively thickly observed levels of participation, first by holding the number of small bidders constant at two and estimating the large firm cost distribution separately for auctions with between two and four large bidders. Next, I hold the number of large firms constant at three and then estimate the small firm cost distribution separately for auctions with between one and three small bidders. This is done for both preference and non-preference auctions and is repeated separately for the 25th, median, and 75th percentile values of the engineer's estimate.

The results are displayed in Figure 5. No clear pattern emerges linking the cost distribution with the number of bidders. In general, the distributions do not line up by the number of bidders, nor do they reveal any particular patterns of selection from different parts of the cost distribution.

\section{BID PREFERENCES AND CONSTRUCTION COSTS}

When bid preferences are invoked and the higher bidding small firm is awarded a procurement contract, the winning small firm often has a higher cost than the lower bidding large firm. To what extent does this contribute to the lower efficiency on preference auctions? To answer this question, it is necessary to compare the cost of the winning firm with the cost of the firm who would have won in the absence of preferences, holding participation fixed. This is complicated for two reasons. First, since preferences have the effect of lowering the equilibrium bid of the large firm, some large firms now will submit the low bid who would not have otherwise. Second, unlike in the case of 
symmetric auctions, Maskin and Riley (2000) show that in an asymmetric auction the low cost firm is not necessarily the auction winner. As a result, efficiency loss could exist even in the absence of bid preferences.

The approach taken in this section is to estimate the extra efficiency loss on bid preference projects by examining the average difference between the winning cost and the lowest cost on preference auctions and comparing this with the the similar difference on non-preference auctions. Comparing these differences will account for both of the potential biases mentioned above. Table 7 shows this comparison. Of 895 preference auctions, the low cost firm loses 42 times compared with six times on the 417 non-preference auctions. The average efficiency loss is $\$ 295$ per preference contract and $\$ 39$ per non-preference contract. This suggests that bid preferences introduce an extra efficiency loss of $\$ 256$ through awarding the contract to higher cost participants, leaving aside their effect on the participation decision. This represents 0.09 percent of the total construction cost on preference contracts. This points toward a relatively small loss in efficiency due to the direct switching effect of preferences.

\subsection{Simulation}

The correlation of participation and the distribution of costs with the preference regime suggests that the entry decisions of firms from different parts of the cost distribution is an important component of the impact of preferences. The reduced form results suggest that participation effects are responsible for most of the higher procurement costs on state funded contracts. This section considers what the preference auctions would have looked like had the participation patterns of firms been unchanged from that observed in non-preference auctions. From this counterfactual, the difference in the winning bid and the construction cost between preference and non-preference auctions can be decomposed into the effects of participation, bidding, and the switching mechanism.

It is also possible that Caltrans is setting its bid preference parameter at a suboptimal level. This section will also consider several counterfactual levels of the bid preference parameter, first allowing participation to vary and then subsequently holding participation constant.

To accomplish this, numerical methods are used to obtain the inverse bid functions of small and large firms for preference auctions under the counterfactual assumption that the distribution and expected number of participants is the same as that observed on non-preference auctions. The inverse bid functions are also obtained for preference and non-preference auctions using the actual participation patterns observed for those auction regimes. From these computed bid functions, a set of auctions can be simulated for three scenarios - non-preference auctions with actual participation, 
preference auctions with the counterfactual non-preference participation, and preference auctions with actual preference participation.

As noted, the system of differential equations defined by the firms' first-order conditions does not have an analytical solution in the case of asymmetric bidders. It is therefore necessary to use numerical methods to solve for the equilibrium bid function. Bajari (2001) suggests parameterizing the bid function as a fifth-order polynomial, and then minimizing the squared deviation between the firm first-order condition over the set of parameters characterizing the bid function of small and large firms. Here I will describe the method first without considering bid preferences, and then describe how bid preferences enter.

Let all firms draw from a cost distribution with support on $[\underline{c}, \bar{c}]$. According to Maskin and Riley (2003), the unique equilibrium is characterized by three conditions.

(i) For each firm, $y_{i}(\bar{c})=\bar{c}$

(ii) At the lowest cost, all firms bid $\beta: y_{i}(\beta)=\underline{c}$

(iii) Each firm's first-order condition holds for all $b$.

Conditions $(i)$ and $(i i)$ describe boundary conditions for each auction participant. These constrain the bid functions to be identical for small and large participants at the endpoints of the cost distribution.

Let the bid function take the form

$$
y_{\tau}(b ; \underline{b}, \alpha)=\underline{b}+\tilde{y_{\tau}}(b ; \alpha)
$$

where

$$
\widetilde{y_{\tau}}(b ; \alpha)=\sum_{k=0}^{5} \alpha_{\tau, k}(b-\underline{b})^{k} .
$$

Let $G_{\tau}(b ; \underline{b}, \alpha)=0$ denote the first-order condition of a firm of type $\tau$. Bajari's method evaluates the first-order conditions on a grid of $k$ uniformly spaced points between $\underline{b}$ and $\bar{b}$. The first-order conditions for each firm at each point in the grid, along with the $2 N$ boundary conditions are used to define a least-squares objective function:

$$
H(b, \alpha)=\sum_{i} \sum_{k} G_{\tau}\left(\operatorname{bgrid}_{k}, \underline{b}, \alpha\right)^{2}+\sum_{i}\left(\underline{c}-y_{\tau}(\underline{b} ; \underline{b}, \alpha)\right)^{2}+\sum_{i}\left(\bar{c}-y_{\tau}(\bar{c} ; \underline{b}, \alpha)\right)^{2} .
$$

Preferences can be included in this model by modifying the boundary conditions $(i)$ and $(i i)$. First, when bidding against small firms in a preference auction, large firms are guaranteed to lose if they bid greater than $\bar{c} / \theta$. Therefore condition $(i)$ for large firms under bid preferences is modified as $y_{\tau}(\bar{c} / \theta)=\bar{c} / \theta$. For costs above $\bar{c} / \theta$, large firms are assumed to bid their cost. Second without 
preferences, the bid at the lowest cost must be the same for the two firms since the marginal competition faced by each at this cost is identical. This relationship is broken with preferences, as the optimal bid for large firms at the lowest cost will now be lower than the optimal bid for small firms. With preferences, therefore, condition $(i i)$ is altered to allow $\underline{b}$ to vary depending on the firm type. Therefore, equation (16) becomes

$$
y_{\tau}(b ; \underline{b}, \alpha)=\underline{b}_{\tau}+\widetilde{y_{\tau}}(b ; \alpha)
$$

so that $\underline{b}_{\tau}$ varies by bidder type $\tau$.

To implement this method, the cost distribution estimated in section 5.2 is parameterized using a Weibull distribution:

$$
f_{\tau}\left(c \mid \theta, z_{0}\right)=\alpha_{\tau}(\theta) \beta_{\tau}(\theta) c^{\left(\alpha_{\tau}(\theta)-1\right)} e^{-\left(c / \beta_{\tau}(\theta)\right)^{\alpha_{\tau}(\theta)}}
$$

where $\alpha_{\tau}(\theta)$ and $\beta_{\tau}(\theta)$ are type-specific parameters that depend on the preference regime, and $z_{0}$ represents the engineer's estimate. This distribution has support over positive values of $c$, and allows for a non-symmetric cost distribution. The parameters of $f_{\tau}\left(c \mid \theta, z_{0}\right)$ are estimated for $z_{0}=\operatorname{med}(z)$ by minimizing the squared distance between the Weibull density and kernel density estimates evaluated at the median of the engineer's estimate. Figure 6 shows the estimated kernel densities against the fitted weibull densities. The weibull density estimates seem to capture the important features of the data, though perhaps with too much density in the lower portion of the distribution. The cost support $[\underline{c}, \bar{c}]$ used for the numerical computation of the bid function and later simulations is [50000,700000]. These provide a range of plausible values that are also more than one bandwidth away from the boundary of the support of the empirical distribution.

Using the above methodology, the bid function for preference and non-preference auctions will be computed for three cases - non-preference auctions with observed non-preference participation patterns, preference auctions with participation patterns observed on non-preference auctions, and finally preference auctions with observed preference participation patterns. For each of these three cases, the number of small and large participants will be drawn with probability $p\left(n_{s}, n_{l} \mid \theta\right)$, which is obtained from the observed fraction of auctions with preference level $\theta$ having $n_{s}$ small and $n_{l}$ large bidders. For each of these participants, a cost will be drawn from the estimated Weibull distribution $f_{\tau}\left(c \mid \theta, z_{0}\right)$. Finally, a bid for each firm is generated from the inverse bid function $y_{\tau}\left(b \mid \theta, n_{s}, n_{l}, f_{\tau}\left(c \mid \theta, z_{0}\right)\right)$. This allows the effect of preferences to be evaluated under actual participation patterns as well as the counterfactual participation patterns observed in non-preference auctions. 


\section{RESULTS}

Figures 7 and 8 display the computed bid functions for small and large firms when $n_{s}=2$ and $n_{l}=3$. This number of small and large firms is near the average number of participants observed in the data. The effect of preferences on the computed bid function is small but fits closely with expectations. At a given cost bid preferences lower the equilibrium large firm bid. The effect of preference auctions is dampened by the participation effect. Having higher cost participants shifts the bid function up for the case with actual participation in preference auctions relative to the counterfactual case using non-preference participation. A similar pattern emerges from the small firm bid functions. Holding participation constant, bid preferences shift up the bid function for small firms. Allowing the participation to differ shifts the small firm bid function up even further since in preference auctions each small firm faces higher cost competitors. For both small and large firms, the bids of the lowest cost firms are affected the most, and this effect is most pronounced among small firms.

Table 8 displays the simulation results. In column (1), the average outcomes for small and large bidders is described for non-preference auctions. Large firms tend to have lower cost, and this cost difference is amplified by the fact that there are more large firms. Consistent with having lower average costs, large firms have a slightly higher mark-up of bids over costs.

In Column (2), preferences are added to the model holding fixed participation patterns. Consistent with this, the average number of small and large firms is virtually identical with those in the simulation of column(1). Small firms seem to benefit from the introduction of preferences, while large firms earn lower profits. The average large firm reduces its bid by $\$ 2723$, while the average small firm increases its bid by $\$ 2673$. This is also reflected in average markups, which are 1.0 percentage points higher for small firms and 1.1 percentage points lower for large firms. The lower profits earned by large firms translates into a winning bid that is $\$ 837$ lower in preference auctions. This suggests that had the participation of large firms remained constant across preference and non-preference auctions, procurement costs would have fallen as suggested by theory. The winning cost is $\$ 238.4$ higher in the auctions in preferences, which is similar to the efficiency loss estimated directly from the pseudo-costs reported in Table 7.

Next, column (3) describes the results from simulated preference auctions where the number and distribution of firms matches that observed in actual preference auctions. The higher cost set of participants has two conflicting effects on the bids of firms. Each firm faces weaker competition, which tends to increase bids. However, the average firm has higher costs, leading to a lower ability to markup bids over costs. The first effect seems stronger, as the markups of small and large firms 
are higher when competition is weaker. Finally, the weaker set of participants results in a higher average winning construction cost. The cost of the average winning firm is $\$ 204,375,3.6$ percent higher than for non-preference auctions. This increase in construction costs is due mostly to the effect of participation, which apparently swamps the impact of preferences occasionally switching to higher cost firms.

An often stated goal of providing preferential treatment to small firms is to put them on a more level footing. To evaluate the success of the program in meeting this objective, I also provide for each of these simulations the fraction of contracts awarded to small firms and the average dollar value across all auctions awarded to small firms. We see that preferences increase the fraction of contracts going to small firms from 0.36 with no bid preferences to 0.39 with bid preferences. Also, this leads to a 20 percent increase in the dollar value of contracts awarded to small firms. Given the simulated procurement cost and efficiency effects, we can evaluate the cost effectiveness of the program. With participation allowed to adjust on preference auctions, each additional dollar going to small firms leads to a 20 cent increase in government costs and a 27 cent loss in economic efficiency. If the program could be designed to ameliorate participation effects, perhaps by expanding its reach to all contracts, the program would be less successful at increasing purchases from small businesses. In this case, it would only increase purchases 9.4 percent. However this increase would be achieved much less costly. The efficiency loss per additional dollar going to small businesses would cost 3.4 cents in efficiency and actually reduce government expenditures.

\subsection{Counterfactual Bid Preference Levels}

While bid preferences induce a strategic response on the part of large firms, any downward effect this has on the winning bid is swamped by the adverse participation effect at the current level of bid preferences. In this section I consider whether the government could do better by choosing a different bid preference parameter. To do so, I simulate auctions at different levels of the bid preference parameter, allowing participation patterns to vary across different levels of participation. To approximate the how counterfactual bid preference parameters alter the number and distribution of participants, I linearly extrapolate the parameters from the $0 \%$ and $5 \%$ preference level cases to other bid preference levels. Using this method, the probability of observing $n_{s}$ small firms and $n_{l}$ large firms in the $\theta \%$ preference case is approximated by $p_{n s n l}^{\theta}=(1-\theta / 5) p_{n s n l}^{0}+(\theta / 5) p_{n s n l}^{5}$. A similar interpolation is used to approximate the parameters of the Weibull distribution of firm costs. 
Once the approximated participation probabilities and Weibull parameters are obtained, firm bid functions are computed numerically for each level of participation as outlined previously. I then simulate 10,000 auctions at each level of the counterfactual bid preference. Figure 9 plots the average winning bid for each level of $\theta$. From this figure we see that bid preferences increase procurement costs at each level of $\theta$.

I next performed a similar exercise holding constant participation at the non-preference levels. The participation probabilities, $p_{n s n l}$, and cost distribution parameters are fixed at the nonpreference level. I then computed numerically the bid strategies conditional on this participation at the counterfactual levels of $\theta$ and simulated 10,000 auctions at each of the bid preference levels. The average winning bid at each $\theta$ is plotted in Figure 9. In contrast to the case where participation is allowed to vary along with bid preferences, the fixed-participation case shows that the gradient of the winning bid is negative for low levels of $\theta$ and then increasing for higher levels of $\theta$. Interestingly, this figure suggests that the state is currently setting bid preferences close to the optimal level if it was able to induce the same level of participation on preference and non-preference auctions.

In Table 9 I break down the effect of bid preferences into three components: the average markup of large firms, the average markup of small firms, and the average efficiency loss. We see that increasing bid preferences reduces the large firm markup and increases the small firm markup in a more or less uniform manner. Efficiency loss increases rapidly as preferences increase, moving from $\$ 26.2$ (0.01\% of the winning bid) for no bid preferences to $\$ 438.6$ (0.17 percent of the winning bid) for the 8 percent preference level. The adverse effects of efficiency loss seem to overtake the strategic effects at the 7 percent bid preference level. The preference level that achieves the minimum winning bid is 6 percent, however this is also similar to the average winning bid at the 4 percent bid preference level.

\section{Conclusion}

Public procurement of goods and services is a significant means of redistribution across economic agents. Bid preferences have the potential to achieve redistribution while at the same time lowering procurement costs to the government. This paper shows that preferences may lower procurement costs at little cost to efficiency, holding the participation of firms constant. However, entry is endogenous to the preference regime used. The effects of participation on procurement costs and economic efficiency swamp the effects of preferences on bidding behavior. A majority of the participation effect is due to the substitution between auctions, indicating that the state would likely do 
better if it were able to extend the bid preference program to all auctions it administers. In fact, I find that if participation were not adversely affected by bid preferences, the current preference rate of five percent would be close to optimal. This suggests that participation is a primary concern when considering procurement policies that treat firms asymmetrically.

Furthermore, the adverse effect of bid preferences on procurement costs is not by itself evidence that the program is suboptimal. McAfee and McMillan (1989) show that if the favored group's profits enter positively into the social welfare function, then the optimal bid preference is always positive. While weaker in their conclusions, Naegelen and Mougeot (1998) and Branco (1994) also show that favoritism could lead to positive optimal bid preferences even if an increase in procurement costs results. Even still, there is reason to believe that California is not setting the preference schedule in an optimal manner. Since the preference amount is capped at $\$ 50,000$, the size of the preference declines relative to a firm's bid for bids greater than $\$ 1$ million. This means that for larger projects, as the project size increases the preference percentage declines. However, as project size increases, the costs of small firms increase more than proportionally. Consequently, it is possible that the preference percentage should be increasing rather than decreasing as projects get larger, depending on how the participation patterns of firms are altered.

An important limitation of this paper is that it does not consider the long-run impacts of bid preferences on market structure. Bid preferences might act to distort firm investment incentives. Since the criteria for program eligibility is based on firm revenues and number of employees, bid preferences could impact the optimal firm size. If there are scale effects, for example through learning by doing, then the preference program could induce some firms to choose a firm size that is inefficient. ${ }^{19}$ The true efficiency loss of the bid preference program may be understated as a result. Conversely, if the bid preference program leads to higher survival rates for small firms, then the number of firms in the market will increase leading to more competition in the market. The existing evidence regarding the impact of procurement policies on the number and size of firms is limited and suggests future research. ${ }^{20}$

\footnotetext{
${ }^{19}$ Jofre-Bonet and Pesendorfer (2003) find that past completion of projects does not lead to lower current bids in road construction projects, suggesting that learning-by-doing is not empirically important.

${ }^{20}$ Exceptions to this include Chay and Fairlie (1998), Myers and Chan (1996), and Bates and Williams (1996), who consider the effect of preferential treatment in procurement for minorities and women on entrepreneurship and firm survival.
} 


\section{References}

[1] Athey, Susan, Jonathan Levin, and Enrique Seira. (2004) "Comparing Open and Sealed Bid Auctions: Theory and Evidence from Timber Auctions," Working Paper, Stanford University.

[2] Ayres, Ian and Peter Cramton. (1996) "Deficit Reduction Through Diversity: How Affirmative Action at the FCC Increased Auction Competition," Stanford Law Review 48:4, pp. 761-815.

[3] Bajari, Patrick. (2001) "Comparing Competition and Collusion in Procurement Auctions: A Numerical Approach," Economic Theory 18, pp. 187-205.

[4] Bates, Timothy and Darrell Williams. (1996) "Do Preferential Procurement Programs Benefit Minority Business?" The American Economic Review, 86:2, 294-97.

[5] Branco, Fernando. (1994) "Favoring Domestic Firms in Procurement Contracts," Journal of International Economics 37:1-2, pp. 65-80.

[6] Cabral, Luis and Shane Greenstein. (1990) "Switching Costs and Bidding Parity in Government Procurement of Computer Systems," Journal of Law, Economics, and Organization 6:2, 453-469.

[7] Chay, Kenneth and Robert Fairlie. (1998) "Minority Business Set-Asides and Black SelfEmployment." Mimeo, U. of California, Berkeley.

[8] Corns, Allen and Andrew Schotter. (1999) "Can Affirmative Action Be Cost Effective? An Experimental Examination of Price-Preference Auctions," The American Economic Review $89: 1$, p. 291-305.

[9] Denes, Thomas A. (1997) "Do Small Business Set-Asides Increase the Cost of Government Contracting?" Public Administration Review, 57:5 (1997), 441-44.

[10] Elyakime, B., J. J. Laffont, P. Loisel, and Q. Vuong. (1994) "First-Price Sealed-Bid Auctions with Secret Reservation Prices," Annales dEconomie et de Statistique, 34, p. 115141.

[11] Flambard, Veronique and Isabelle Perrigne. (2006) "Asymmetry in Procurement Auctions: Some Evidence from Snow Removal Contracts," The Economic Journal 116, p. 1014-1036.

[12] Guerre, E., I. Perrigne, and Q. Vuong. (2000) "Optimal Nonparametric Estimation of FirstPrice Auctions," Econometrica 68:3, pp. 525-574

[13] Haile, Philip A., Han Hong and Michael Shum. (2003) "Nonparametric Tests for Common Values at First-Price Sealed Bid Auctions," NBER Working Paper \#10105.

[14] Hardle, Wolfgang. (1991) Smoothing Techniques With Implementation in S, New York: Springer-Verlag.

[15] Harstad, Ron, Michael Rothkopf, and Yuhong Fu. (2003) "Is Subsidizing Bidders Actually Costly?" Management Science 49:1, 71-84.

[16] Hong, Han and Matthew Shum. (2002) "Increasing Competition and the Winner's Curse: Evidence from Procurement," Review of Economic Studies 69, p. 871-898. 
[17] Jofre-Bonet, Mireia and Martin Pesendorfer. (2003) "Estimation of a Dynamic Auction Game," Econometrica 71:5, pp. 1443-89.

[18] Krasnokutskaya, Elena. (2002) "Identification and Estimation in Highway Procurement Auctions with Unobserved Heterogeneity," Yale Working Paper.

[19] Krasnokutskaya, Elena and Katja Seim. (2006) "Bid Preference Programs and Participation in Highway Procurement Auctions," working paper, University of Pennsylvania.

[20] Li, Tong, Isabelle Perrigne, and Quang Vuong. (2000) "Conditionally Independent Private Information in OCS Wildcat Auctions," Journal of Econometrics 98, 129-161.

[21] Lowinger, Thomas C. (1976) "Discrimination in Government Procurement of Foreign Goods in the U.S. and Western Europe," Southern Economic Journal, 42:3, p. 451-460.

[22] Marion, Justin. (2006) "How Costly is Affirmative Action? Government Contracting and California's Proposition 209," Working Paper, University of California, Santa Cruz.

[23] Maskin, Eric and John Riley. (2000) "Asymmetric Auctions," The Review of Economic Studies 67:3, pp. $413-38$.

[24] - (2003) "Uniqueness of equilibrium in sealed high-bid auctions," Games and Economic Behavior 45:2, p. 395-409.

[25] McAfee, R. Preston and John McMillan. (1989) "Government Procurement and International Trade," Journal of International Economics 26:3-4, pp. 291-308.

[26] Myers, Samuel and Tsze Chan. (1996) "Who Benefits from Minority Set-Asides? The Case of New Jersey." Journal of Policy Analysis and Management, 15:2, pp. 202-226.

[27] Myerson, Roger B. (1981) "Optimal Auction Design." Mathematics of Operations Research, 6:1, pp. 58-73.

[28] Naegelen, Florence and Michel Mougeot. (1998) "Discriminatory Public Procurement Policy and Cost Reduction Incentives," Journal of Public Economics 67:3, pp. 349-367.

[30] Rezende, Leonardo. (2004a) "Biased Procurement Auctions," Working Paper, University of Illinois.

[30] - (2004b) "Auction Econometrics in Least Squares," Working Paper, University of Illinois.

[31] Vagstad, Steinar. (1995) "Promoting fair competition in public procurement," Journal of Public Economics 58, 283-307. 
Figure 1: Propensity to Claim Small Business Status Among Firms that Ever Did

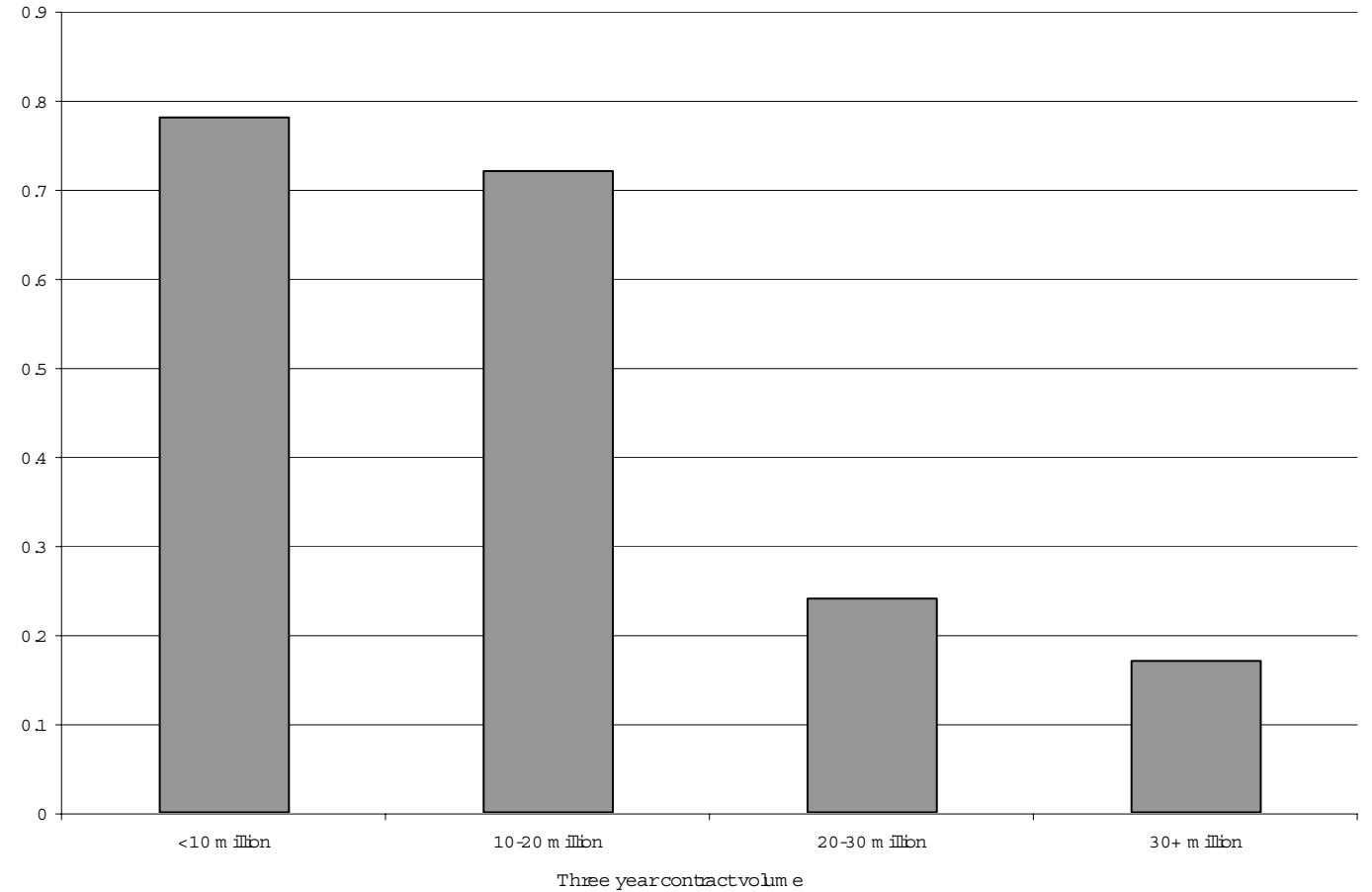


Figure 2: Kernel Estimates of Density of Bid Values Relative to Engineer's Estimate
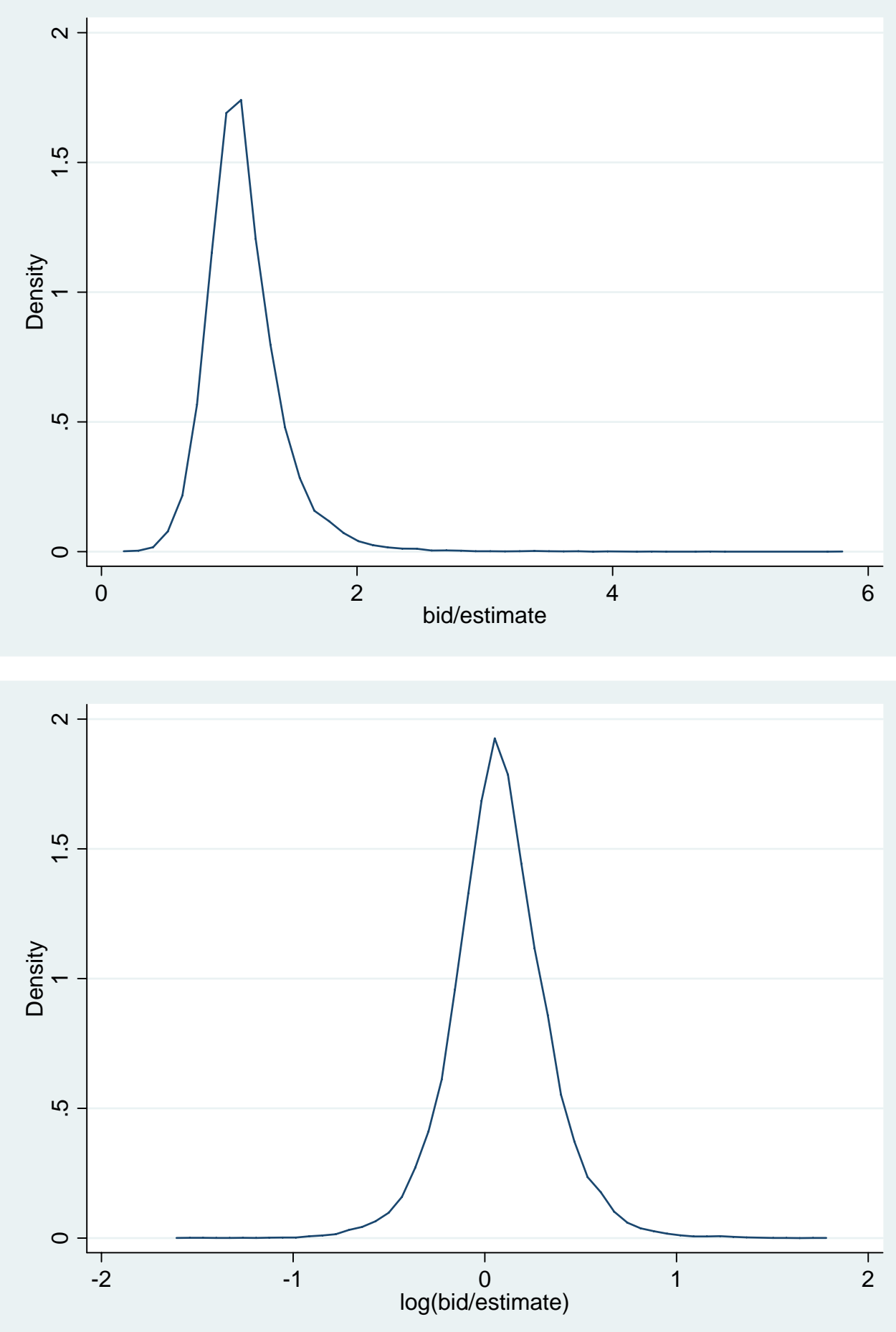
Figure 3: Conditional Distribution of Firm Costs, Evaluated at the Median of the Engineer's Estimate for Non-Preference Auctions

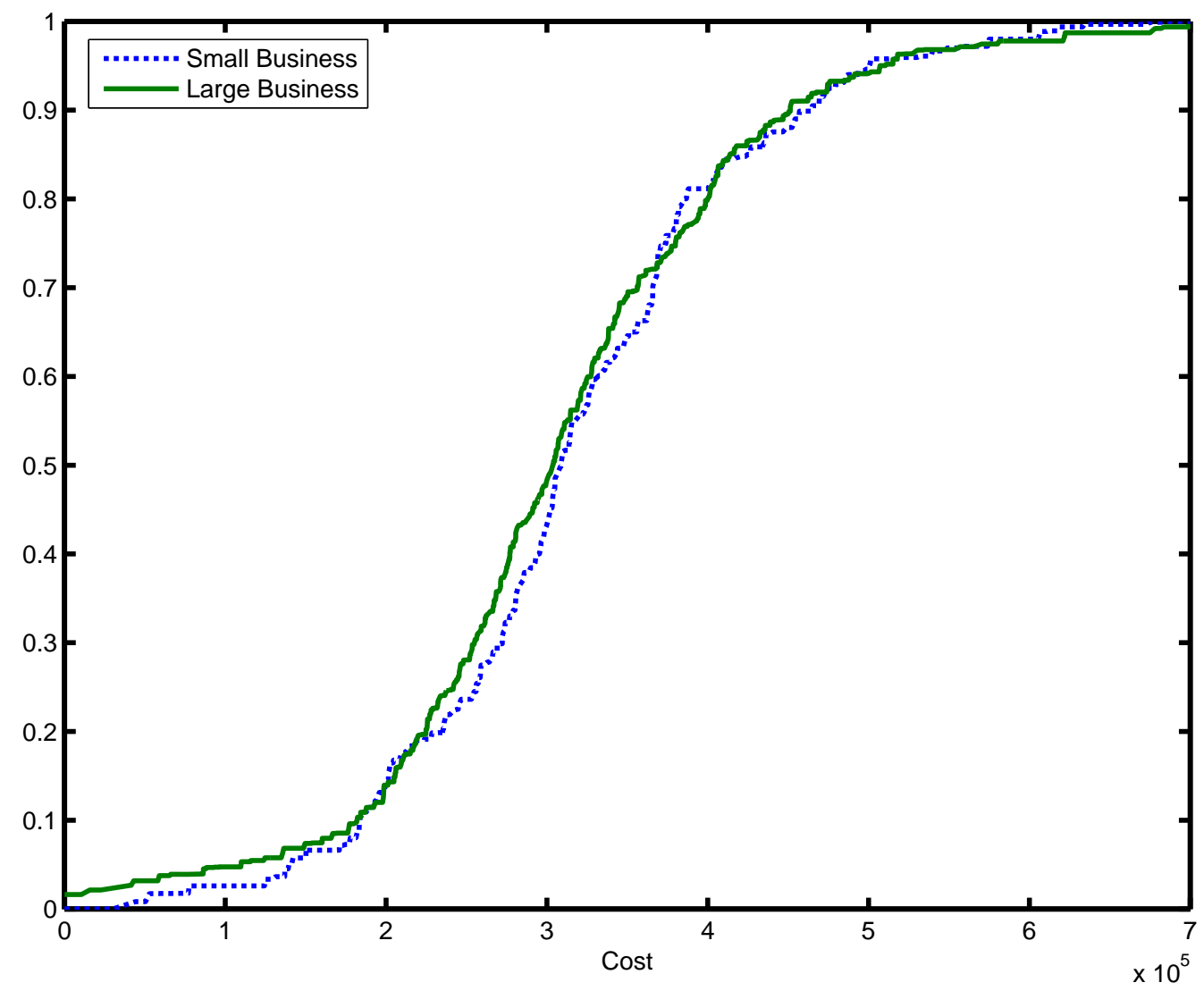


Figure 4: Conditional Distribution of Firm Costs, Evaluated at the Median of the Engineer's Estimate for Preference Auctions

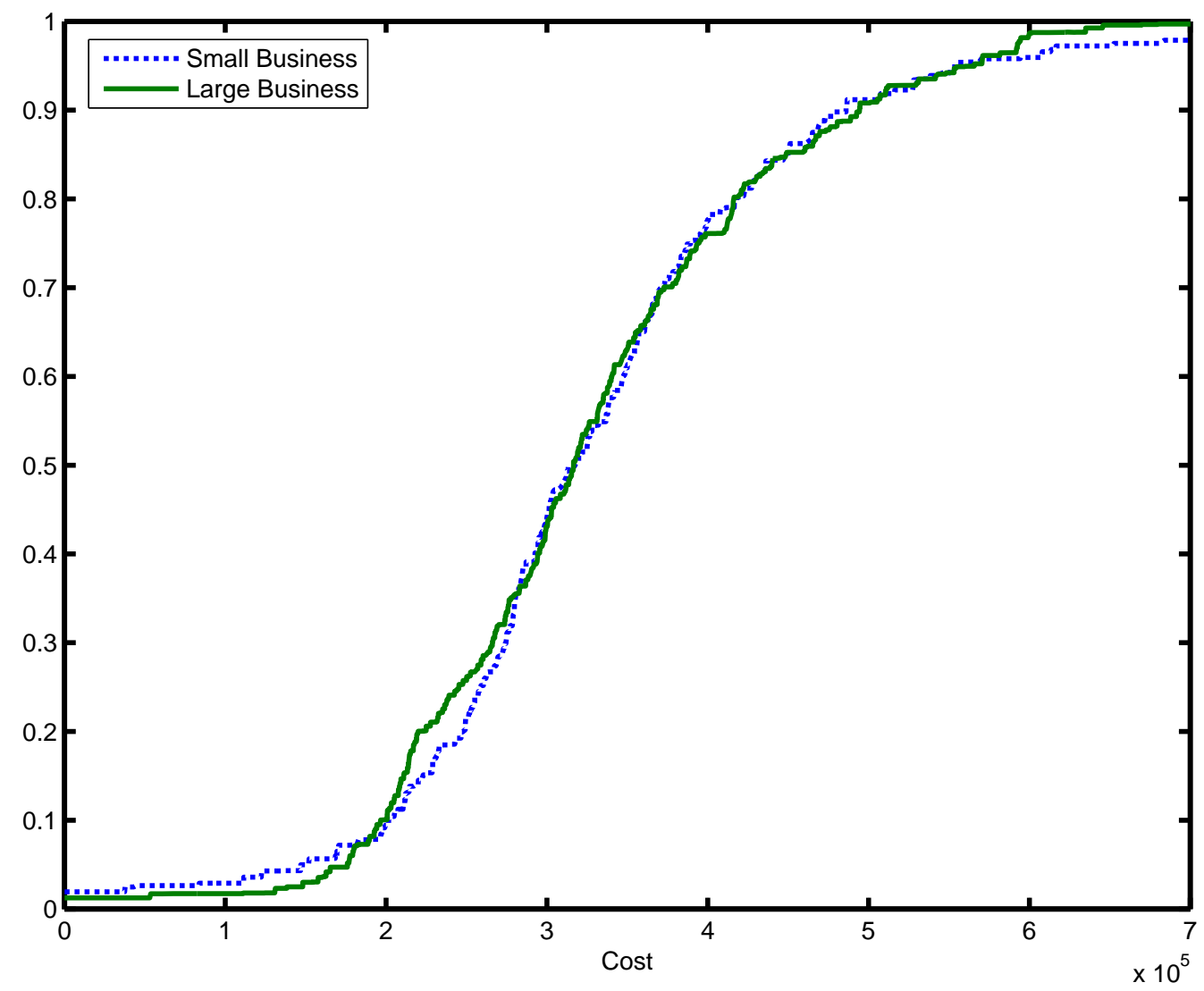


Figure 5: Distribution of Firm Costs for Different Engineer's Estimates and Participation Levels
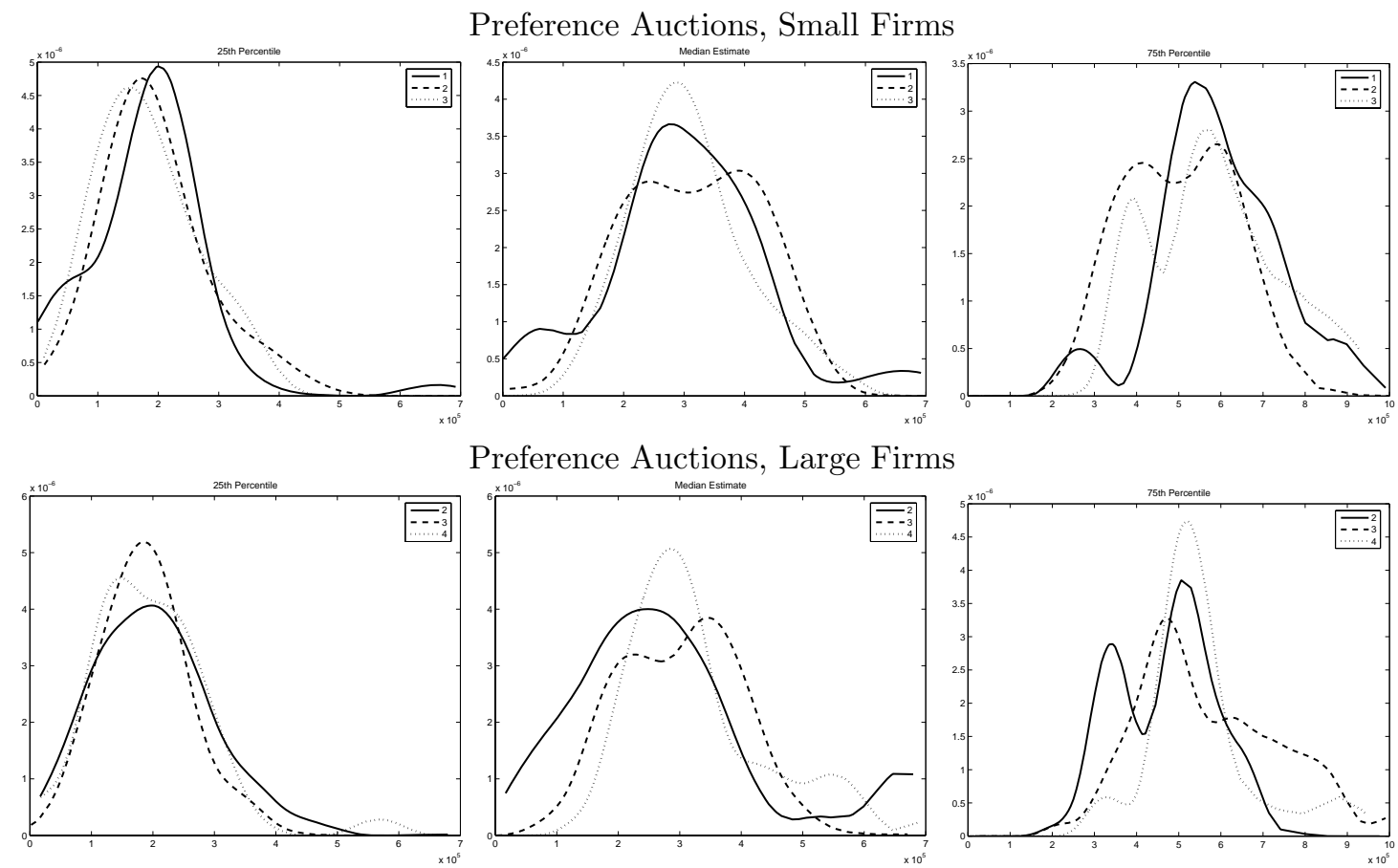

Preference Auctions, Large Firms
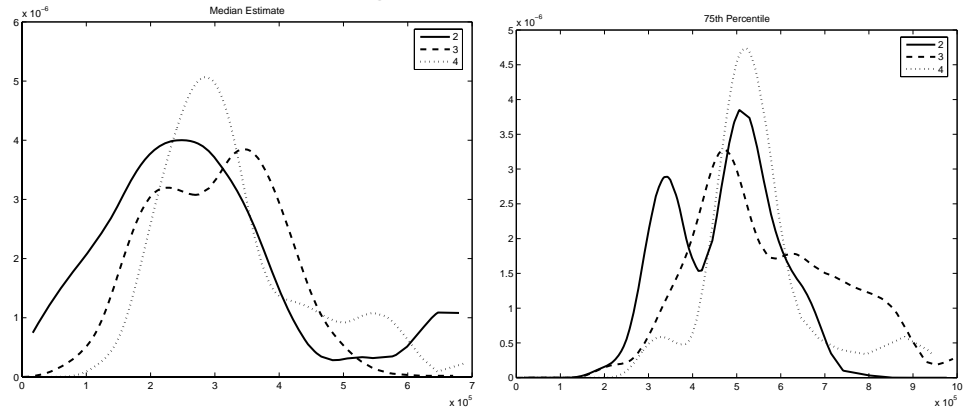

Non-Preference Auctions, Small Firms
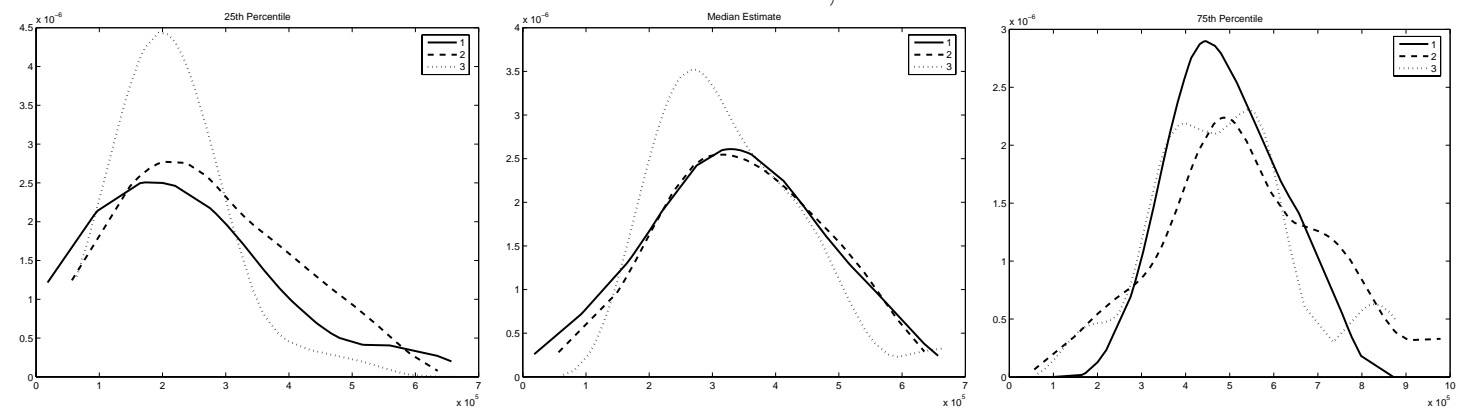

Non-Preference Auctions, Large Firms
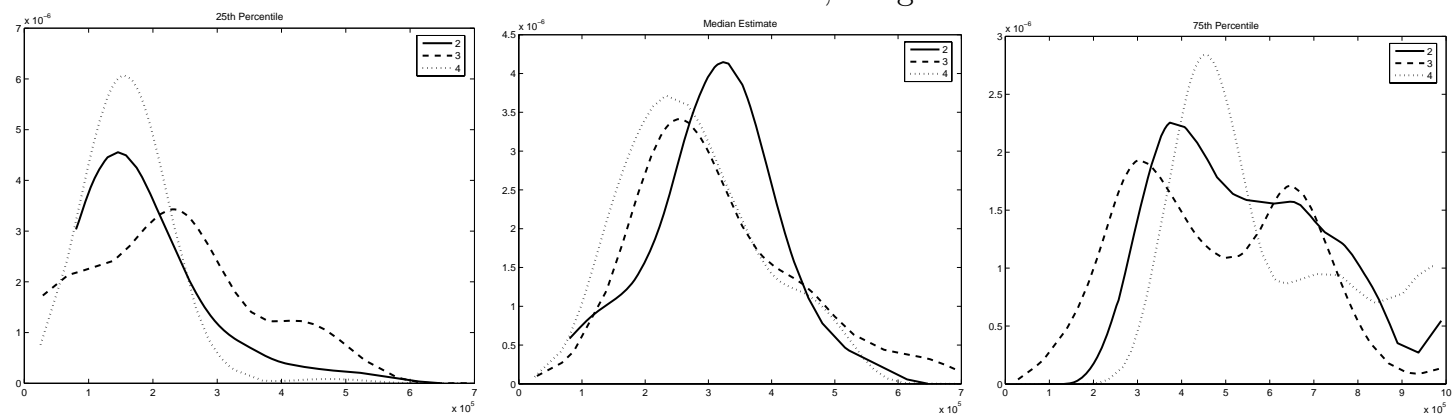

This figure displays the estimated cost distributions by participation level. The figures from left to right describe estimated distributions for projects in the 25th, 50th, and 75th percentile. The estimated distributions shown for small firms hold the number of large bidders constant at three, while varying the number of small bidders from one to three. The estimated distributions shown for large firms hold the number of small bidders constant at two, while varying the number of large bidders from two to four. 
Figure 6: Fit of Weibull to Kernel Density Estimates

\section{Preference Auctions}
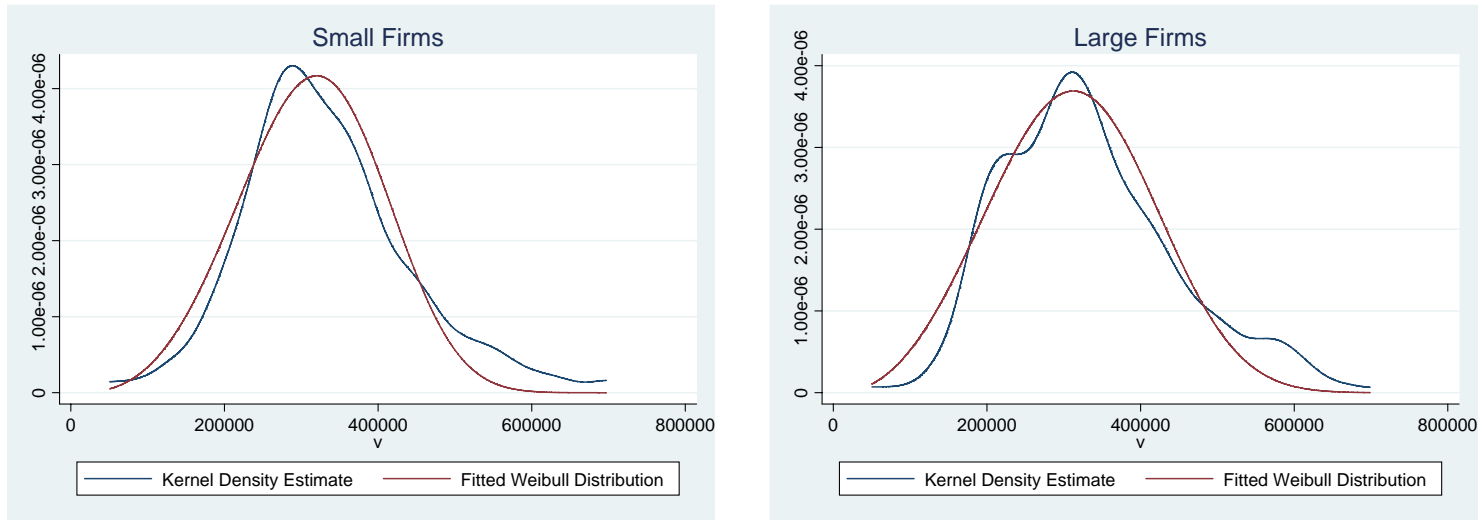

Non-preference Auctions
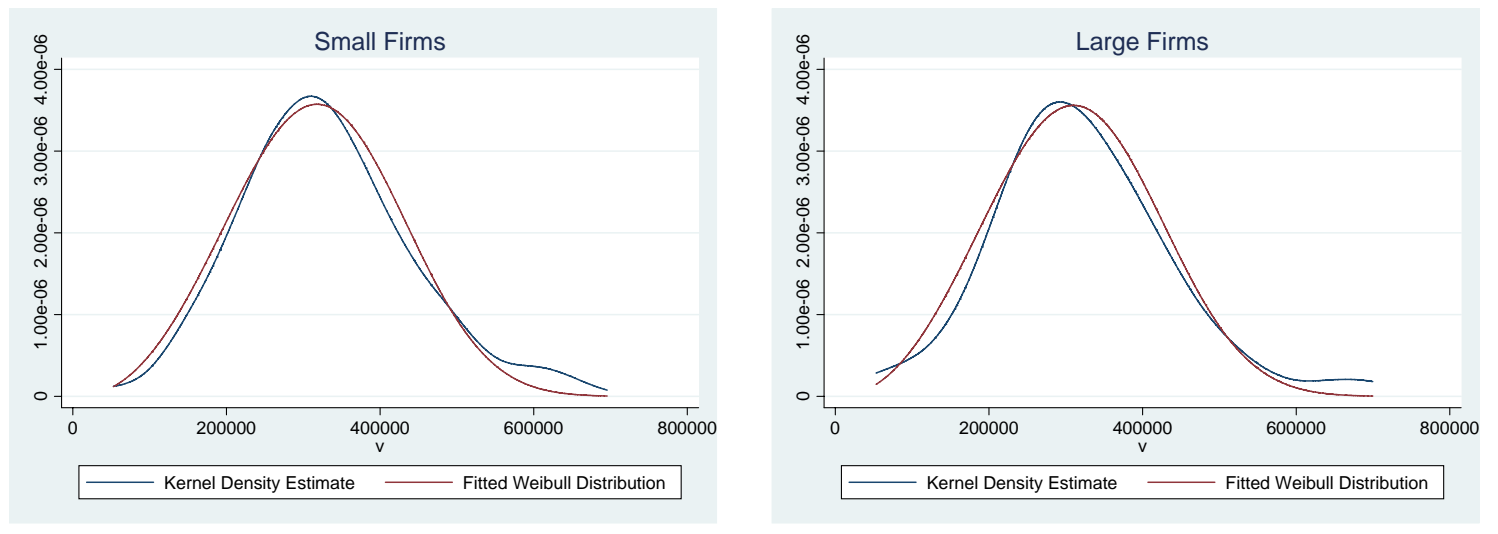

These figures show Weibull density estimates of firm costs. The parameters of the Weibull distribution were estimated by nonlinear least squares, minimizing the squared difference between the Weibull density and the kernel density estimates over a grid of points. 
Figure 7: Large Firm Bid Function, $n_{s}=2, n_{l}=3$

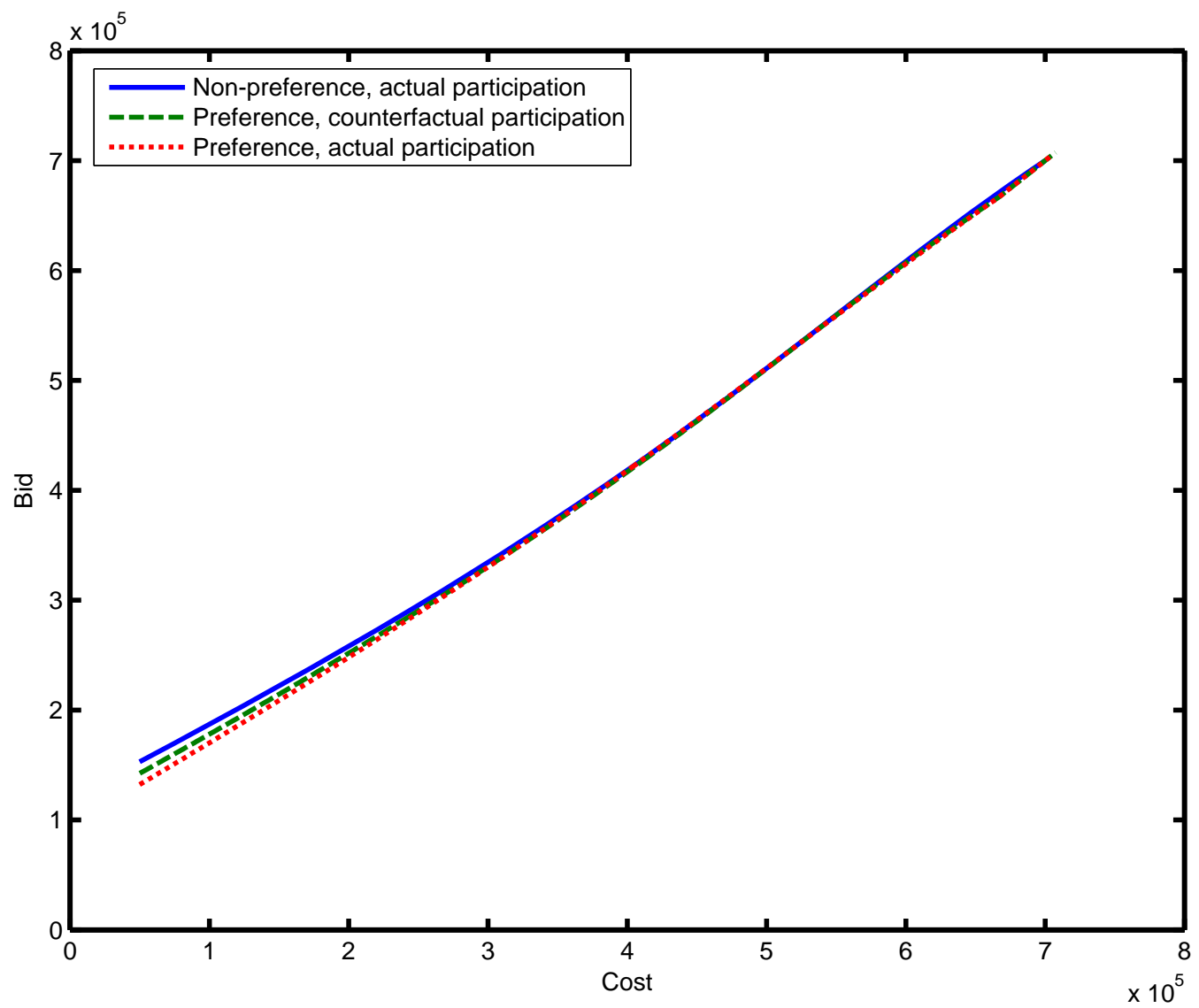


Figure 8: Small Firm Bid Function, $n_{s}=2, n_{l}=3$

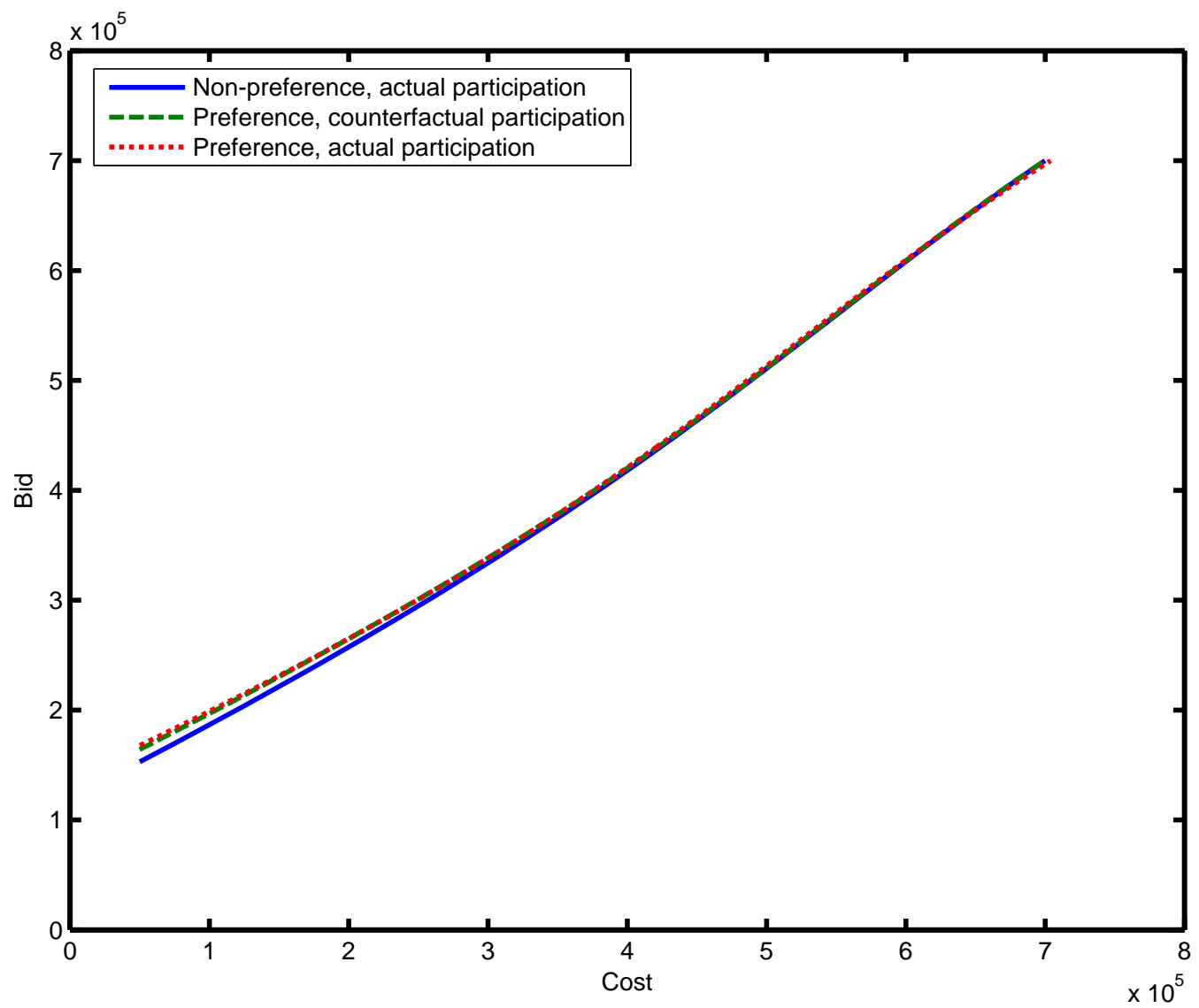


Figure 9: Average Winning Bid, Counterfactual Preference Levels

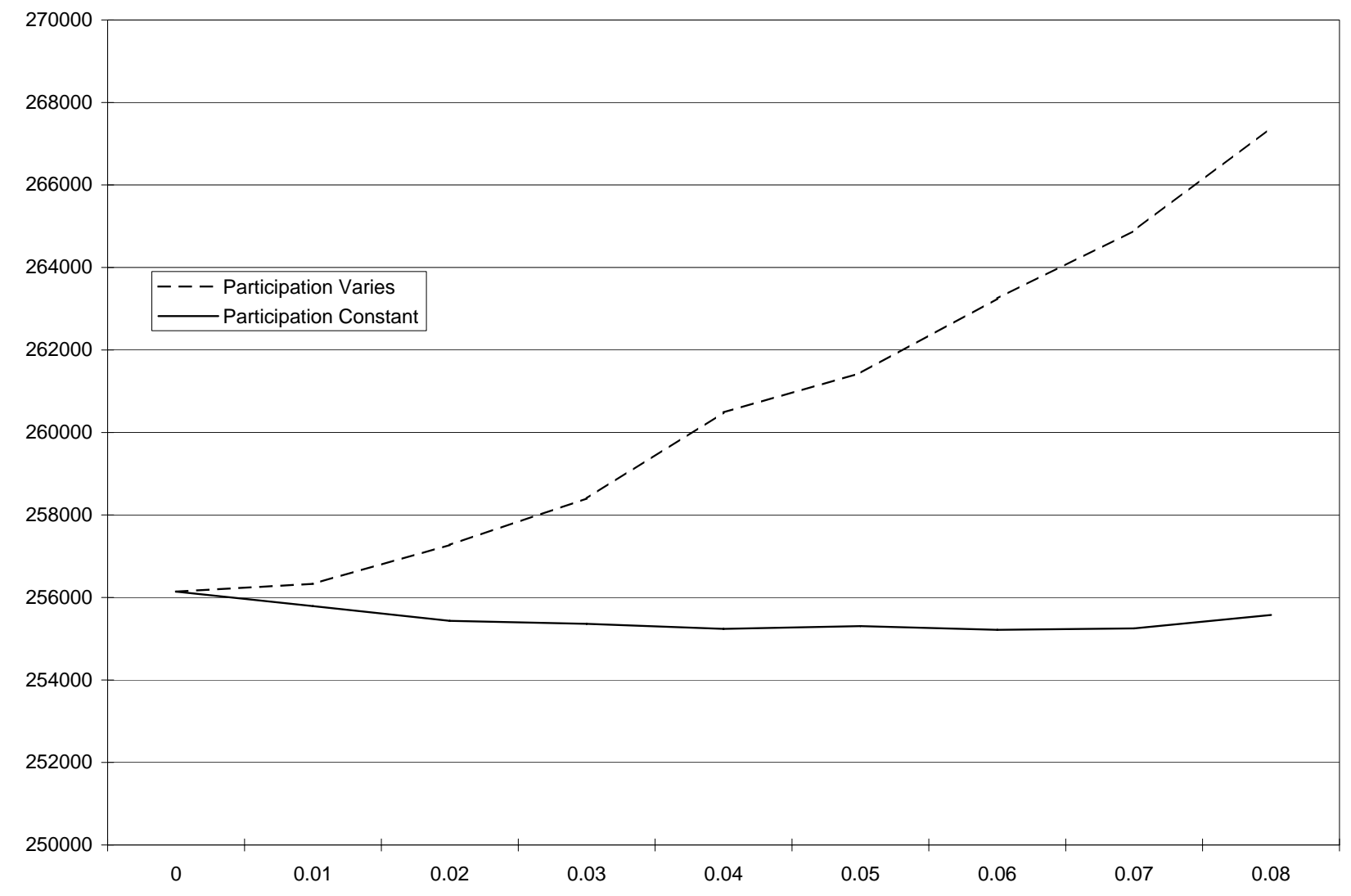

This figure displays the simulated winning bid at different bid preference percentages, holding the participation levels fixed at their non-preference levels. 
Table 1: Summary Statistics

\begin{tabular}{|c|c|c|}
\hline \multirow{2}{*}{ Panel A: All projects } & \multirow[t]{2}{*}{ State funded Contracts } & \multirow[t]{2}{*}{ Federal-aid contracts } \\
\hline & & \\
\hline Contracts & 2091 & 2045 \\
\hline Median winning bid & $\$ 0.33$ million & $\$ 1.25$ million \\
\hline Median Engineer's Estimate & $\$ 0.35$ million & $\$ 1.34$ million \\
\hline Avg. Small bidders & 2.21 & 1.50 \\
\hline Avg. Large bidders & 3.05 & 3.89 \\
\hline Proportion of small bids that win & 0.188 & 0.135 \\
\hline Proportion of large bids that win & 0.191 & 0.205 \\
\hline Fraction of winners small & 0.41 & 0.20 \\
\hline Winner changed by preference & 0.065 & - \\
\hline \multicolumn{3}{|l|}{ Fraction of auctions by type of road: } \\
\hline State highway & 0.64 & 0.66 \\
\hline Interstate & 0.08 & 0.08 \\
\hline U.S. Highway & 0.13 & 0.10 \\
\hline Other & 0.23 & 0.20 \\
\hline \multicolumn{3}{|l|}{ Fraction of auctions by type of project: } \\
\hline Road Construction and Repair & 0.50 & 0.64 \\
\hline Bridge Construction and Repair & 0.05 & 0.06 \\
\hline Landscaping & 0.06 & 0.09 \\
\hline Drainage & 0.05 & 0.05 \\
\hline \multicolumn{3}{|c|}{ Panel B: Projects where estimate $<\$ 1$ million } \\
\hline Contracts & 1789 & 823 \\
\hline Median winning bid & $\$ 0.28$ million & $\$ 0.42$ million \\
\hline Median Engineer's Estimate & $\$ 0.29$ million & $\$ 0.45$ million \\
\hline Avg. Small bidders & 2.42 & 2.33 \\
\hline Avg. Large bidders & 2.89 & 3.66 \\
\hline Proportion of small bids that win & 0.188 & 0.145 \\
\hline Proportion of large bids that win & 0.192 & 0.186 \\
\hline Fraction of winners small & 0.45 & 0.34 \\
\hline Winner changed by preference & 0.073 & - \\
\hline \multicolumn{3}{|l|}{ Fraction of auctions by type of road: } \\
\hline State highway & 0.64 & 0.70 \\
\hline Interstate & 0.09 & 0.07 \\
\hline U.S. Highway & 0.13 & 0.09 \\
\hline Other & 0.23 & 0.18 \\
\hline \multicolumn{3}{|l|}{ Fraction of auctions by type of project: } \\
\hline Road Construction and Repair & 0.52 & 0.53 \\
\hline Bridge Construction and Repair & 0.05 & 0.04 \\
\hline Landscaping & 0.07 & 0.11 \\
\hline Drainage & 0.06 & 0.07 \\
\hline
\end{tabular}


Table 2: Preference auctions and the winning bid

\begin{tabular}{lccc}
\hline & $(1)$ & $(2)$ & $(3)$ \\
\hline Preference Auction & 0.038 & 0.020 & -0.005 \\
& $(0.012)^{* * *}$ & $(0.012)^{*}$ & $(0.013)$ \\
Ln(Eng. Estimate) & 0.972 & 0.976 & 0.974 \\
& $(0.010)^{* * *}$ & $(0.009)^{* * *}$ & $(0.010)^{* * *}$ \\
Number of workdays (X100) & 0.005 & 0.001 & -0.003 \\
& $(0.004)$ & $(0.003)$ & $(0.005)$ \\
Number of items (X100) & 0.368 & 0.418 & 0.295 \\
& $(0.047)^{* * *}$ & $(0.046)^{* * *}$ & $(0.059)^{* * *}$ \\
DBE participation goal & 0.218 & 0.194 & 0.095 \\
& $(0.132)^{*}$ & $(0.132)$ & $(0.139)$ \\
Constant & 0.178 & 0.190 & -0.581 \\
& $(0.151)$ & $(0.145)$ & $(0.348)^{*}$ \\
Bidder Controls? & & $\mathrm{X}$ & $\mathrm{X}$ \\
Firm Effects? & & & $\mathrm{X}$ \\
Observations & 2609 & 2609 & 2607 \\
R-squared & 0.90 & 0.91 & 0.95 \\
\hline
\end{tabular}

The dependent variable is the log of the winning bid.

Each specification controls for road, county, year, and month effects, as well as dummies indicating the broad category of work. $L N(\widetilde{E N G E S T})$ is the log of the engineer's estimate relative to its mean.

$*, * *, * * *$ denote significance at the $90 \%, 95 \%$, and $99 \%$ level, respectively.

Robust standard errors in parentheses. 


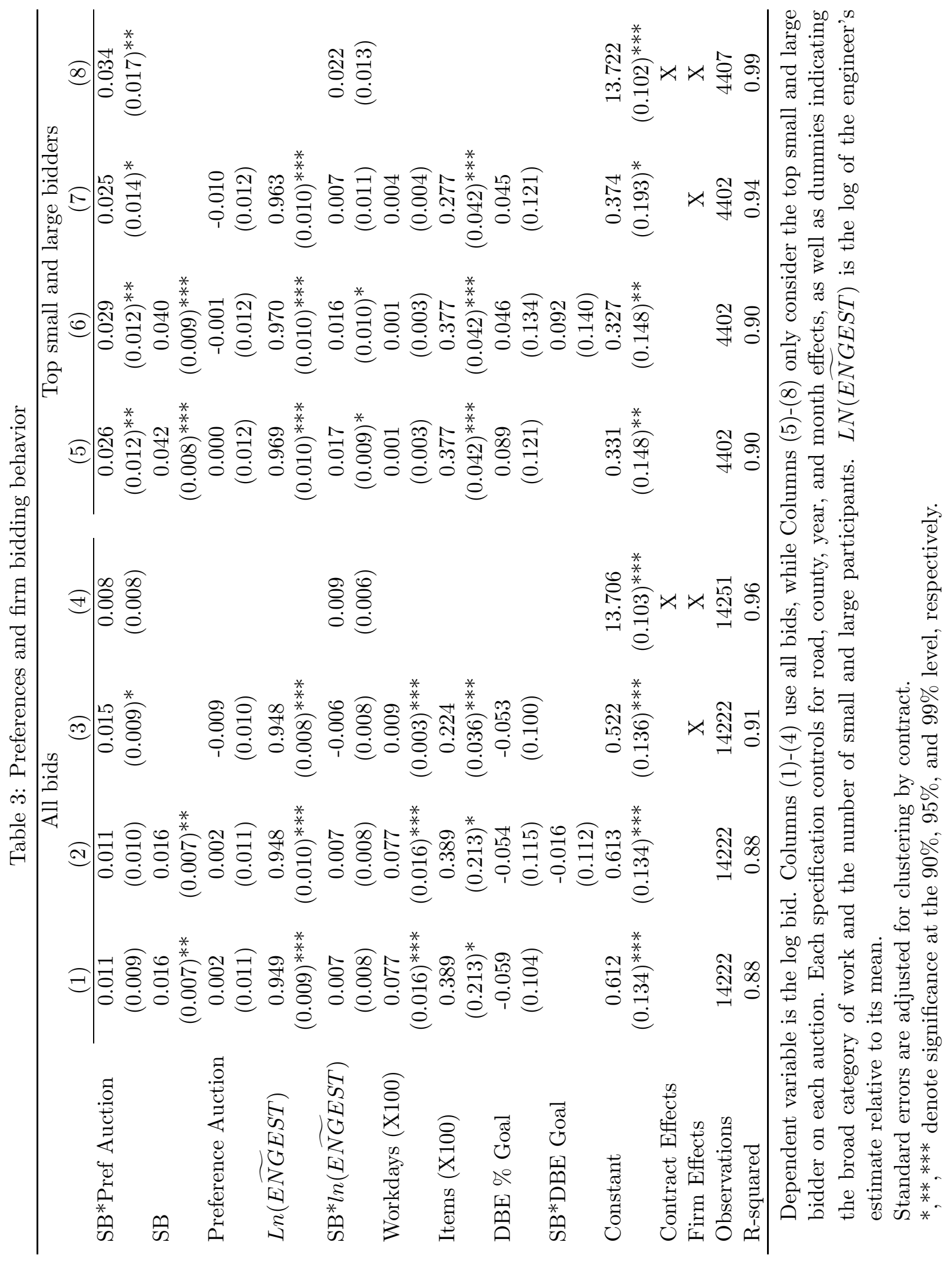


Table 4: Selection regressions

Dependent variable:

\begin{tabular}{|c|c|c|c|c|c|c|}
\hline \multirow[b]{2}{*}{ Preference auction } & \multicolumn{3}{|c|}{ Small bidders } & \multicolumn{3}{|c|}{ Large bidders } \\
\hline & $\begin{array}{c}0.083 \\
(0.092)\end{array}$ & $\begin{array}{c}-0.118 \\
(0.137)\end{array}$ & $\begin{array}{c}-0.255 \\
(0.207)\end{array}$ & $\begin{array}{c}-0.743 \\
(0.085)^{* * *}\end{array}$ & $\begin{array}{c}-0.494 \\
(0.131)^{* * *}\end{array}$ & $\begin{array}{c}-0.821 \\
(0.188)^{* * *}\end{array}$ \\
\hline Pref.*(\% pref. next 6 wks.) & & & $\begin{array}{c}0.307 \\
(0.332)\end{array}$ & & & $\begin{array}{c}0.636 \\
(0.302)^{* *}\end{array}$ \\
\hline$\%$ Pref next 6 weeks & & & $\begin{array}{l}-0.186 \\
(0.283)\end{array}$ & & & $\begin{array}{l}-0.265 \\
(0.258)\end{array}$ \\
\hline \# Upcoming auctions & & & $\begin{array}{c}-0.019 \\
(0.009)^{* *}\end{array}$ & & & $\begin{array}{c}-0.015 \\
(0.008)^{*}\end{array}$ \\
\hline Controls? & No & Yes & Yes & No & Yes & Yes \\
\hline $\mathrm{N}$ & 2612 & 2609 & 2584 & 2612 & 2609 & 2584 \\
\hline $\mathrm{R} 2$ & 0.00 & 0.36 & 0.37 & 0.03 & 0.33 & 0.34 \\
\hline
\end{tabular}

Controls include the engineer's estimate, number of workdays, number of items, indicators for the type of work to be performed, plus year, county and road effects. Considers only projects where the engineer's estimate $<\$ 1$ million.

The variable $\%$ pref represents the fraction of contracts up for bid within the following six weeks that use state funds and are under $\$ 1$ million.

$*, * *,{ }^{* * *}$ denote significance at the $90 \%, 95 \%$, and $99 \%$ level, respectively.

Table 5: Mean number of high-cost and low-cost bidders

\begin{tabular}{lcc}
\hline & Preference Auctions & Non-preference Auctions \\
\hline Low cost small bidders & 1.10 & 1.08 \\
High cost small bidders & 1.32 & 1.25 \\
Low cost large bidders & 1.43 & 1.92 \\
High cost large bidders & 1.41 & 1.65 \\
$\mathrm{~N}$ & 1796 & 829 \\
\hline
\end{tabular}

Firm is defined as low cost if its firm effect from a regression of log bid on preference*sb interaction, small business dummy, preference auction indicator, and controls is below the within-type median. 
Table 6: Number of bid observations by number of bidders

Panel A: Preference Auctions

\begin{tabular}{llllllllllllll}
\hline \multirow{1}{*}{ Small Large bidders } & & & 0 & 1 & 2 & 3 & 4 & 5 & 6 & 7 & 8 & 9 & 10 \\
& & 0 & 22 & 184 & 267 & 228 & 80 & 90 & 21 & 0 & 0 & 0 \\
& 1 & 15 & 134 & 339 & 436 & 370 & 204 & 119 & 40 & 27 & 20 & 22 \\
2 & 32 & 225 & 328 & 415 & 318 & 203 & 104 & 36 & 70 & 0 & 0 \\
& 3 & 57 & 208 & 315 & 288 & 238 & 136 & 54 & 90 & 22 & 24 & 26 \\
4 & 60 & 175 & 276 & 294 & 144 & 90 & 60 & 44 & 12 & 13 & 14 \\
5 & 55 & 108 & 182 & 80 & 63 & 80 & 22 & 48 & 13 & 42 & 0 \\
6 & 66 & 77 & 112 & 135 & 40 & 66 & 24 & 0 & 42 & 0 & 0 \\
7 & 35 & 88 & 117 & 80 & 66 & 12 & 52 & 0 & 15 & 0 & 0 \\
8 & 16 & 27 & 50 & 22 & 84 & 26 & 14 & 0 & 32 & 0 & 0 \\
9 & 9 & 20 & 44 & 12 & 0 & 14 & 45 & 16 & 17 & 0 & 0 \\
10 & 0 & 11 & 12 & 13 & 0 & 0 & 16 & 0 & 18 & 0 & 0
\end{tabular}

Panel B: Non-preference Auctions

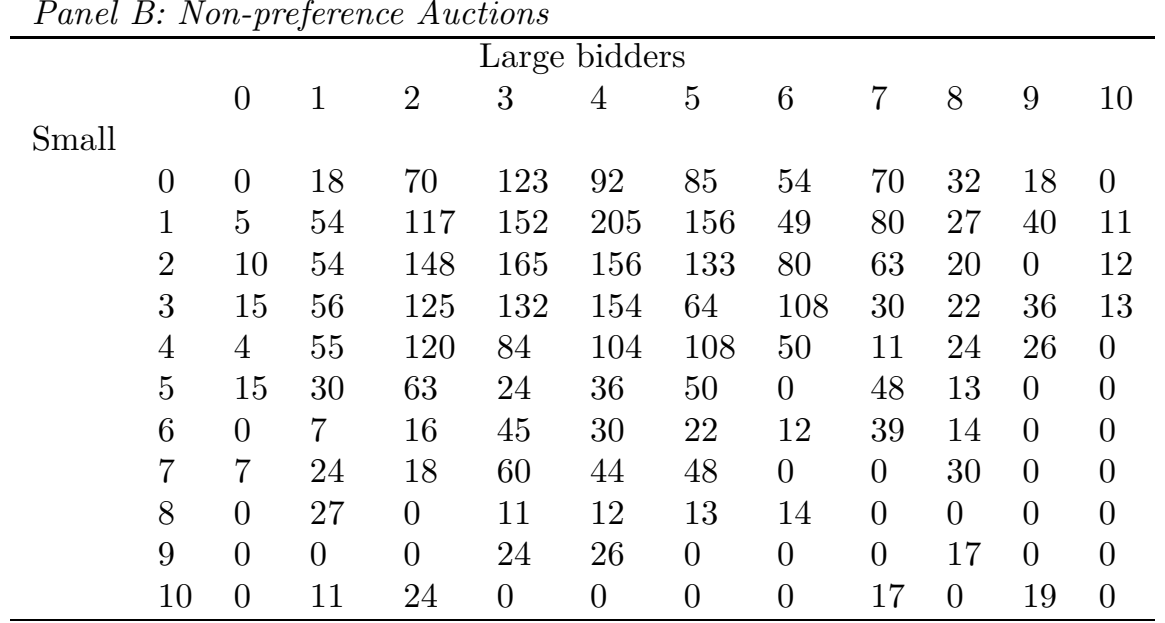

Table 7: Bid Preferences and Construction Costs

Low cost firm loses

Number of auctions

Avg. Procurement cost

Preference Auctions Non-preference Auctions

Low cost firm loses

895
278226.7
42
294.82

417

Efficiency loss/contract

294.82

336780.8

6

39.05

Difference:

$\$ 255.77$

As \%

$0.09 \%$ 
Table 8: Simulation results: Preferences, Participation, and Efficiency

\begin{tabular}{lccc}
\hline & Non-preference simulations & \multicolumn{2}{c}{ Preference Simulations } \\
Assumed Participation: & Actual & Counterfactual & Actual \\
\hline & $(1)$ & 346.4 & 356.8 \\
\hline Large firm bid & 349.2 & $14.3 \%$ & $13.1 \%$ \\
Large firm margin & $15.4 \%$ & 274.7 & 282.5 \\
Low large firm bid & 278.6 & & \\
& & 361.3 & 362.5 \\
Small firm bid & 358.6 & $14.1 \%$ & $15.8 \%$ \\
Small firm margin & $13.1 \%$ & 321.6 & 326.9 \\
Low small firm bid & 318.0 & & \\
& & 255.3 & 261.4 \\
Winning bid & 256.1 & 197.6 & 204.4 \\
Winning cost & 197.3 & 0.383 & 0.390 \\
Fraction Awarded to Small Firms & 0.360 & 100.7 & 108.2 \\
Average $\$$ Awarded to Small Firms & 92.0 & & \\
& & 2.11 & 2.08 \\
$n_{s}$ & 2.11 & 3.29 & 3.06 \\
$n_{l}$ & 3.27 & & \\
Simulated auctions & 10000 & 10000 & 10000 \\
\hline
\end{tabular}

These are average results for 10000 simulated auctions in thousands of dollars, where the number of participants are drawn with probabilities matched to those in the data. Each participant is given a cost draw from a Weibull distribution, whose parameters are fit to match kernel density estimates of costs at the median of the engineer's estimate.

Column (1) displays simulations of non-preference auctions using participation patterns and cost distributions observed from participants in non-preference auctions.

Column (3) shows simulations of preference auctions using participation and cost distributions estimated from preference auctions.

Column (2) presents the counterfactual exercise where preference auctions are simulated using participation probabilities and cost distributions from non-preference auctions. 
Table 9: Simulation results: Counterfactual Preferences, Participation Constant

\begin{tabular}{lcccc}
\hline Bid Preference & Winning bid & Efficiency Loss & Large Firm \% Markup & Small Firm \% Markup \\
\hline & & & & \\
0 & 256,142 & 26.2 & 15.4 & 13.1 \\
0.01 & 255,790 & 29.5 & 15.1 & 13.4 \\
0.02 & 255,433 & 51.0 & 14.8 & 13.5 \\
0.03 & 255,361 & 94.4 & 14.6 & 13.7 \\
0.04 & 255,239 & 156.1 & 14.4 & 13.9 \\
0.05 & 255,305 & 208.9 & 14.3 & 14.3 \\
0.06 & 255,215 & 263.9 & 14.1 & 14.5 \\
0.07 & 255,250 & 361.6 & 13.9 & 14.7 \\
0.08 & 255,576 & 438.6 & 13.8 & . \\
\hline
\end{tabular}

These are average results for 10000 simulated auctions in thousands of dollars, where the number of participants are drawn with probabilities matched to those observed in non-preference auctions. Each participant is given a cost draw from a Weibull distribution, whose parameters are fit to match kernel density estimates of costs in non-preference auctions at the median of the engineer's estimate. 